\title{
Motor symptoms in Parkinson's disease: A unified framework
}

\author{
Ahmed A. Moustafa, 1,2,3, Srinivasa Chakravarthy ${ }^{4}$, Joseph R. Phillips ${ }^{2}$, Ankur Gupta ${ }^{4}$, \\ Szabolcs Keri ${ }^{5,6}$, Bertalan Polner ${ }^{5}$, Michael J. Frank7, Marjan Jahanshahi ${ }^{8}$ \\ ${ }^{1}$ Department of Veterans Affairs, New Jersey Health Care System, East Orange, NJ. \\ ${ }^{2}$ School of Social Sciences and Psychology $\& 3$ Marcs Institute for Brain and Behaviour, \\ Western Sydney University, Sydney, New South Wales, Australia. \\ ${ }^{4}$ Department of Biotechnology, Indian Institute of Technology, Madras, Chennai, India. \\ ${ }^{5}$ Nyírö Gyula Hospital, National Institute of Psychiatry and Addictions, Budapest, \\ Hungary; Department of Cognitive Science, Budapest University of Technology and \\ Economics, Budapest, Hungary. \\ ${ }^{6}$ Department of Physiology, Faculty of Medicine, University of Szeged, Hungary \\ ${ }^{7}$ Department of Cognitive, Linguistic Sciences and Psychological Sciences, Brown \\ Institute for Brain Science, Brown University, Providence RI 02912, USA. \\ ${ }^{8}$ Cognitive Motor Neuroscience Group and Unit of Functional Neurosurgery, Sobell \\ Department of Motor Neuroscience and Movement Disorders, UCL Institute of \\ Neurology, The National Hospital for Neurology and Neurosurgery London, UK.
}

To whom correspondence should be addressed,

\author{
Ahmed A. Moustafa, \\ School of Social Sciences and Psychology \& Marcs Institute for Brain and Behaviour, \\ Western Sydney University, Sydney, NSW. \\ Email: a.moustafa@westernsydney.edu.au
}

Key words: Parkinson's disease, tremor, akinesia, bradykinesia, rigidly, freezing of gait, handwriting, grip force, speech.

Acknowledgment: we thank Mac Shine for providing help with writing and input on the manuscript. 


\begin{abstract}
Parkinson's disease (PD) is characterized by a range of motor symptoms. Besides the cardinal symptoms (akinesia and bradykinesia, tremor and rigidity), PD patients show additional motor deficits, including: gait disturbance, impaired handwriting, grip force and speech deficits, among others. Some of these motor symptoms (e.g., deficits of gait, speech, and handwriting) have similar clinical profiles, neural substrates, and respond similarly to dopaminergic medication and deep brain stimulation (DBS). Here, we provide an extensive review of the clinical characteristics and neural substrates of each of these motor symptoms, to highlight precisely how PD and its medical and surgical treatments impact motor symptoms. In conclusion, we offer a unified framework for understanding the range of motor symptoms in PD. We argue that various motor symptoms in PD reflect dysfunction of neural structures responsible for action selection, motor sequencing, and coordination and execution of movement.
\end{abstract}




\section{Introduction}

Parkinson's disease (PD) is a degenerative neurological disorder, associated with primary (akinesia, bradykinesia, tremor, rigidity, and postural instability) and secondary motor symptoms (e.g. gait disturbance, micrographia, precision grip impairment, and speech problems) (Jankovic \& Tolosa, 2007; Lees, Hardy, \& Revesz, 2009). Although it has been assumed that the various motor symptoms in PD were caused solely by striatal dopamine depletion (Kalia, Brotchie, \& Fox, 2013; Xia \& Mao, 2012), many studies have shown that additional neural structures and neurochemical systems were also responsible for the occurrence of motor symptoms in PD; these include prefrontal cortical areas and the cerebellum, as well as serotonergic, glutamatergic, and cholinergic systems (Bohnen et al., 2013; Fox, 2013).

\section{A unified framework to understand motor symptoms in PD}

In the current review, we attempt to explain commonalities among different motor symptoms in PD. We argue that by investigating subprocesses of motor behavior, one may find links among different motor symptoms in PD. This is motivated by studies showing overlapping neural areas underlying different motor processes in PD. In addition, many studies have reported significant correlations among different motor symptoms in PD, including gait and speech (Cantiniaux et al., 2010; Giladi et al., 2001; Goberman, 2005; Moreau et al., 2007; Nutt et al., 2011), speech and hand movement (Skodda, Visser, \& Schlegel, 2011), gait and hand movements (Naismith \& Lewis, 2010; Vercruysse et al., 2012), handwriting and primary motor symptoms (Wagle Shukla et al., 2012), speech production and other motor processes including gait and facial movements (Goberman, 2005), and saccadic eye movements and finger and body movement (Shibasaki, Tsuji, \& Kuroiwa, 1979). 
Complex motor behaviors, such as gait, speech and handwriting, rely on simpler motor processes, which include the selection of appropriate motor actions, sequencing of movements, coordination of different motor effectors, correct execution of these sequences of movements, as well as the integration of perceptual input with timing information (see Figure 1). Here, we propose that correlations among different motor symptoms in PD, especially those affecting speech, hand motor control and gait, are due to sharing many of more elemental motor processes. Cortical areas also play a role in some of these motor processes (see Table 1 and data reviewed above). Despite similarities in the component processes, these complex movements, however, differ in several aspects, including how they are impacted by stimuli and environmental cues. For example, environmental stimuli has more influence on gait than on speech, as the former involves the continuous updating of perceptual information.

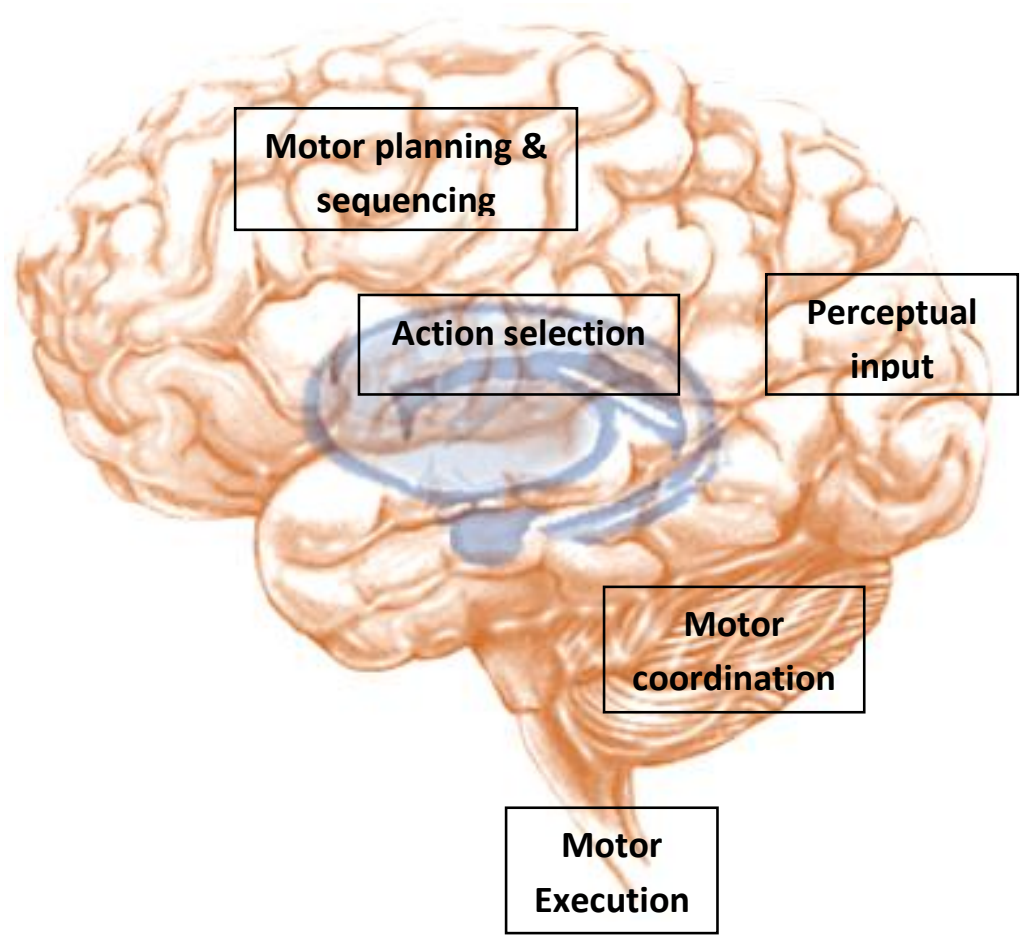


Figure 1: Motor performance relies on elemental motor processes including action selection (basal ganglia), sequencing and planning of motor actions (motor cortical regions), and motor coordination and timing (cerebellum), among others. We hypothesize that gait, handwriting, and speech are composed of the integration of these elemental motor processes depicted in the figure. Future computational and simulation studies should clarify how these brain regions interact to produce such complex motor behavior.

Crucially for the present review, there is a dearth of functional magnetic resonance imaging (fMRI) studies on motor production. This is possibly because motor responses or movement of any type can easily introduce motion-induced signal changes that confound the blood-oxygen-level dependent (BOLD) activation signals of interest. Those studies that mainly discuss the neural substrates of motor output were added to the review. In this review, we will first describe in detail the clinical and neural profile of a range of motor symptoms in PD. This will include primary symptoms that are considered to be cardinal features of the disorder, such as akinesia, bradykinesia, tremor, and gait disturbances, and also some secondary symptoms that have been highlighted as central to the Parkinsonian phenotype, such as impairment of handwriting, speech and precision grip. At this point, we inform the reader here that wwe provided a critical review of the literature on postural instability elsewhere (Crouse, Phillips, Jahanshahi, \& Moustafa, 2016). Our goal is to summarize recent research in order to compare the effects of PD and associated treatments on each motor symptom in turn. In addition, we will also highlight potential relationships amongst various motor symptoms of $\mathrm{PD}$, such as whether severity of tremor or akinesia impact gait or handwriting; or whether freezing of gait and speech deficits have overlapping neural mechanisms. Importantly, in writing this review, we did not aim to provide a complete overview of existing studies for each motor symptom in PD, as these issues have been more 
than adequately covered in other reviews (Helmich, Hallett, Deuschl, Toni, \& Bloem, 2012; Jankovic, 2008).

In conclusion, we are going to present a unified framework that explains how interactions among brain regions might explain different motor symptoms of PD. By doing so, we wish to provide insight into why pharmacological and neurosurgical treatments are effective only for a restricted set of motor symptoms, and why certain, seemingly distant motor symptoms show covariation. The ultimate aim of this review is twofold: we intend to pave the way for novel computational models that can account for multiple motor PD symptoms simultaneously, and we also hope that this review can benefit the development of comprehensive treatments for motor symptoms.

\section{a- Primary motor symptoms: Akinesia and bradykinesia, rigidity, and tremor}

\section{Clinical features}

Akinesia (poverty of action, difficulty initiating movements,) and bradykinesia (slow movements) are considered among the primary motor features in PD. Rigidity is associated with feeling of stiffness experienced by the patient, and clinicians may assess rigidity by examining the resistance of a muscle against passive stretching. Interestingly, clinically assessed severity of rigidity was found to correlate with the magnitude and duration of the long-latency reflex (Berardelli, Sabra, \& Hallett, 1983). With respect to tremor, one may distinguish between resting, postural, and kinetic manifestations of the symptom. Resting tremor (which occurs at rest) is the most common form of tremor in $\mathrm{PD}$, while action/kinetic tremor (which is tremor that occur during voluntary movements) and postural tremor (inability to maintain stable posture against gravity) (Toth, Rajput, \& Rajput, 2004) are more common in essential tremor (Bhidayasiri, 2005). However, it is often difficult to dissociate PD from essential tremor (Thenganatt \& Louis, 2012). Fahn (2011) added intention tremor 
(i.e. tremor that occurs and grows as patient approaches a target during visually guided movements, Zakaria et al., 2013), although very few studies have focused on this kind of tremor. Tremor can affect the hands, the feet, and to a lesser extent, other body parts, either at high or low frequency (8-11 or 4-6 Hz). Approximately 70\% of PD patients experienced tremor during the course of the disease (Helmich et al., 2012).

The clinical diagnosis of PD requires the presence of a subset of motor symptoms (e.g., tremor, rigidity, akinesia, bradykinesia and postural imbalance), therefore the diagnostic system allows for patients with different motor symptom profiles (Hughes, Daniel, Kilford, \& Lees, 1992). Studies often classify PD patients into the tremor-dominant, the akinesiadominant (also known as akineto-rigid), or the mixed phenotype category (Jankovic et al., 1990; Lee et al., 2012; Lewis et al., 2005; Moustafa \& Poletti, 2013; Mure et al., 2011; Poletti, Frosini, et al., 2011; Rajput, 1993; Schiess, Zheng, Soukup, Bonnen, \& Nauta, 2000; Schillaci et al., 2011; Zaidel, Arkadir, Israel, \& Bergman, 2009; Zetusky \& Jankovic, 1985). Although most of these studies did not specify the subtype of tremor that the patients were presenting with, they can help to reveal the clinical correlates and neural substrates of these different motor subtypes (akinesia vs. tremor) in PD. For example, it was found that in the early stages of PD, tremor- and akinesia-dominant patients did not differ in terms of age, disease duration, levodopa dosage, or disease severity (as measured by the Unified Parkinson's Disease Rating Scale - Motor section, UPDRS III) (Eggers, Kahraman, Fink, Schmidt, \& Timmermann, 2011). However, these motor subtypes might have different clinical profiles and outcomes. In a recent longitudinal study, it was found that the akinesiadominant subtype indeed progressed faster than the tremor-dominant one (Eggers et al., 2012; Louis et al., 1999). Studies also found that bradykinesia symptoms are more common among patients with rapid disease progression (Jankovic et al., 1990). Interestingly, a recent study found that $15-38 \%$ of tremor-dominant PD patients converted over time into the mixed 
phenotype, while 46-50\% converted to the akinesia dominant phenotype (Von Coelln et al., 2015), suggesting that these phenotypes might have common clinical and neural substrates.

Further, early studies found that the severity of akinesia and bradykinesia symptoms did not correlate (Evarts, Teravainen, \& Calne, 1981). Similarly, it was reported that resting tremor did not correlate with other primary motor symptoms in PD (Louis et al., 2001). Furthermore, compared to tremor-dominant patients, patients with severe akinesia were more likely to develop dementia (Aarsland, Andersen, Larsen, Lolk, \& Kragh-Sorensen, 2003; Poletti, Emre, \& Bonuccelli, 2011; Poletti et al., 2012; Williams-Gray, Hampshire, Robbins, Owen, \& Barker, 2007). Other studies suggested that tremor symptoms can decrease over the years (Helmich et al., 2012; Toth et al., 2004). This may contribute to the fact that compared to non-tremor patients, tremor-dominant PD patients were found to survive longer (Forsaa et al., 2010; Lo et al., 2009). These data suggest that the different dominant primary motor symptoms of PD are associated with different clinical courses of the illness.

\section{Neural substrates}

The cardinal neural loss in PD is a reduction of dopamine levels in the basal ganglia, particularly the dorsal striatum (Kish, Shannak, \& Hornykiewicz, 1988). However, the primary motor symptoms of PD are associated with dysfunction of different neural areas (Fahn, Libsch, \& Cutler; Fox, 2013; Lewis et al., 2011). Dopamine depletion in the basal ganglia is strongly linked to akinesia and rigidity, while its link to tremor is unclear (Albin, Young, \& Penney, 1989; Helmich, Janssen, Oyen, Bloem, \& Toni, 2011; Rodriguez-Oroz et al., 2009; Rossi et al., 2010; Spiegel et al., 2007). A few studies, for example, have argued that resting tremor is less related to dopamine deficiency, while kinetic and postural tremor are more dopamine dependent, as indicated by the differential effects on dopamine 
medications on each type of tremor (Benamer et al., 2003; Benamer et al., 2000; Pirker et al., 2002; Spiegel et al., 2007).

Studies have found that PD patients with dominant akinesia have more dopamine loss in the striatum (Schillaci et al., 2011) and the globus pallidus (Rajput, Voll, Rajput, Robinson, \& Rajput, 2009), as compared to PD patients with predominant tremor. On the contrary, studies have also report reduced dopamine levels in PD patients with tremor, relative to patients with dominant akinesia (Qamhawi et al., 2015). Similarly, studies have also suggested that excessive inhibitory output from the basal ganglia to cortical areas might be the neural mechanism underlying bradykinesia symptoms (Berardelli, Rothwell, Thompson, \& Hallett, 2001). Computational and mechanistic models suggested that the source of akinesia involves not only hyper-excitability of striatal neurons originating in the indirect pathway leading to (i) suppression of movement and (ii) enhanced motivational cost of movement, but that (iii) a lack of D2 receptor stimulation results in an aberrant learning process which further amplifies such symptoms (Collins \& Frank, 2014; Wiecki \& Frank, 2010). However, other fMRI studies have also shown that hypoactivation of many cortical areas, including supplementary motor and anterior cingulate cortex, may be associated with akinesia symptoms (Sabatini et al., 2000).

Rigidity has been associated with the frequency of neuronal discharge in the subthalamic nucleus (STN) of PD patients. A study has reported that response to placebo, as mirrored in reduction of clinician-rated rigidity of the arm, was associated with reduced firing frequency of STN neurons in PD patients (Benedetti et al., 2004). Another study, however, has reported that in never-medicated early stage PD patients, the activation of the basal ganglia, the thalamus, or motor cortical areas (the primary motor cortex and the supplementary motor area, SMA) during a precision grip force task did not correlate significantly with rigidity (J. Prodoehl, Spraker, Corcos, Comella, \& Vaillancourt, 2010). 
Furthermore, a later study has revealed that severity of rigidity correlated with functional connectivity between the cerebellum, the motor, temporal and occipital cortices, and the nucleus caudatus in mild-moderate PD patients OFF medication, while they were performing a motor task involving external and internal (memory) cues (Baradaran et al., 2013). To sum up, these findings suggested that rigidity is not only associated with STN firing frequency, but also with altered functioning of a widespread brain network.

The neural substrates of tremor are less clear, as tremor has been associated with cerebellar, thalamic, and STN abnormalities (Helmich et al., 2012; Kassubek, Juengling, Hellwig, Spreer, \& Lucking, 2002; Mure et al., 2011; Probst-Cousin, Druschky, \& Neundorfer, 2003; Weinberger, Hutchison, Lozano, Hodaie, \& Dostrovsky, 2009; Zaidel et al., 2009). However, an fMRI study did not report subthalamic activation in relation to tremor in PD (Helmich et al., 2011), which finding differs from intraoperative studies with direct recordings showing that STN neurons that oscillated at tremor frequency (Levy, Hutchison, Lozano, \& Dostrovsky, 2000; Magill, Bolam, \& Bevan, 2001). In addition, Rosenberg-Katz and colleagues (Rosenberg-Katz et al., 2013) found that PD patients with tremor had a lower mean loss of gray matter than non-tremor patients. It was also reported that PD patients with dominant tremor showed more activation in the prefrontal cortex than patients with nondominant tremor (J. Prodoehl et al., 2013).

However, the neural substrates of kinetic tremor are not completely established and require further research by possibly comparing neural activations in PD patients with kinetic or postural vs. resting tremor using fMRI (or comparing neural substrates of different tremors in PD and essential tremor patients). Some have argued that cerebellar activation in PD patients during movement could reflect compensatory mechanisms that counteract the functional impairment of the cortico-striatal motor circuit (Wu \& Hallett, 2013; Yu, Sternad, Corcos, \& Vaillancourt, 2007). One recent study compared motor function in patients with 
PD and essential tremor, and suggested that the cerebellum plays a role in resting and kinetic tremor (Brittain et al., 2015).

\section{Effects of dopamine medications and DBS}

Dopaminergic medications have been shown to be effective in treating akinesia and bradykinesia. Studies have also found that although dopaminergic medications effectively ameliorated bradykinesia, they did not normalize movement speed (Vaillancourt, Prodoehl, Verhagen Metman, Bakay, \& Corcos, 2004). Another study has found that the restoration of SMA activation with apomorphine (a dopamine agonist) was associated with the concomitant improvement of akinesia and bradykinesia (Jenkins et al., 1992). On the other hand, the effects of dopaminergic medications (both levodopa and dopamine agonists) on tremor are inconclusive (Elble, 2002). For example, levodopa has been found to effectively manage resting tremor, while it showed less clinical efficacy, or could even exacerbate kinetic (Solida, Ghika, \& Vingerhoets, 2002) and postural tremor (Pact \& Giduz, 1999; Solida et al., 2002; Uitti, 1998). Other studies have suggested that kinetic and postural tremors might be less responsive to dopaminergic treatment than akinesia and bradykinesia (Fishman, 2008; Koller, Busenbark, \& Miner, 1994). Furthermore, Shapiro and colleagues concluded that rigidity did not always respond well to dopaminergic medication (Shapiro et al., 2007). An interesting study measured local field potentials in the STN of PD patients, in whom levodopa reduced both bradykinesia and rigidity (Kuhn et al., 2009). Curiously, improvement in both symptoms correlated with the suppression of oscillatory power in the STN, regardless of the synchronisation frequency across a broad range $(8-35 \mathrm{~Hz})$.

Deep brain stimulation (DBS) of the STN might have differential effects on akinesia, bradykinesia, and tremor in PD. For example, STN DBS was more effective for treating tremor than akinesia (Schlaier et al., 2014), presumably by reducing the pathology associated 
with abnormal STN oscillations. In addition, DBS of the thalamus was found to be effective in managing tremor, while it was less efficient in improving akinesia and rigidity (Benabid et al., 1996), although some recent studies found different effects of thalamic DBS on the cardinal symptoms of PD (Yamada, Hamasaki, \& Kuratsu, 2014). Moreover, DBS of the STN was found to improve motor symptoms in advanced PD patients and increase glucose metabolism in the right premotor area and the cerebellum. Improvement of rigidity and resting tremor in the left limbs correlated with increase of glucose metabolism in the right premotor area (Nagaoka et al., 2007). Interestingly, in another study, DBS was found to ameliorate rigidity when applied to the bilateral, contralateral and ipsilateral STN, although the greatest improvements were observed for bilateral stimulation (Tabbal et al., 2008). Furthermore, DBS of the internal globus pallidus (GPi) had variable effects on the primary motor symptoms in PD, depending on the contact location within the GPi (Krack et al., 1998). DBS of the STN and the GPi had comparable effects on bradykinesia (Brown et al., 1999). Similar to dopaminergic medications, STN DBS ameliorated bradykinesia but did not completely abolish slowness of movement (Vaillancourt, Prodoehl, et al., 2004). Finally, the impact of dopaminergic medication and DBS on the tremor-dominant versus akineto-rigid subtypes of PD appears to be different (reference needed).

\section{b- Gait impairment in Parkinson's disease}

\section{Clinical features}

Gait disturbance is a common problem for patients with PD. Classically, patients with the disease experience a shuffling gait, in which an individual has great difficulty lifting their feet from the ground, effectively impairing the ability to activate appropriate leg swing and propulsion. Individuals with PD also suffer from a number of paroxysmal deficits in gait, whereby the normal gait cycle is interrupted in the midst of an active motor program. For 
example, an individual can suffer from a marked hastening of footsteps during walking, known as festination. Similarly, individuals can also experience an abrupt cessation of walking, in which the feet 'freeze', causing exacerbation of balance impairment and falls. A study has reported that such freezing of gait (FOG) did not correlate with several PD motor symptoms, such as bradykinesia (Bartels et al., 2003).

\section{Neural substrates}

Effective gait requires the coordination of interconnected circuitry across multiple levels of the nervous system, including the spinal cord, the brainstem, the basal ganglia, the thalamus and the cerebral cortex (Takakusaki, 2008; Takakusaki, Oohinata-Sugimoto, Saitoh, \& Habaguchi, 2004). Interneurons in the spinal cord coordinate rhythmic patterns of activity between lower limb muscles that alter the centre of mass and propel the body forward through space. These lower circuits are controlled hierarchically by cortical systems that in concert with neurons in the cerebellum and basal ganglia, allow for the flexible execution of a range of motor plans across different contexts. With the exception of the spinal cord neurons that control the movements of the lower limbs, there is a great deal of overlap in the neural systems utilized to control both gait and cognition. As such, it is likely that deficits in PD that impair gait function, such as the dopaminergic denervation of the striatum, may at least partially manifest as impairments due to deficiencies in cognitive processes. It should be noted, however, that cholinergic dysfunction might have a role in gait disturbance in PD (Rochester et al., 2012). In addition, a resting state fMRI study has revealed that the severity of FOG was associated with reduced connectivity within a fronto-parietal executive and a temporo-occipital visual network (Tessitore, Amboni, Esposito, et al., 2012). These findings were complemented by a voxel-based morphometry study which reported that FOG in PD 
was associated with reduced gray matter volume in left cuneus, precuneus, lingual gyrus, and posterior cingulate cortex (Tessitore, Amboni, Cirillo, et al., 2012).

Alternatively, the concurrence of cognitive and ambulatory deficits in PD may be due to reliance on compensatory processes. Accumulating evidence implicated the role of the motor circuit between the putamen and the SMA in 'automatic' behaviors, and compelling evidence supported the dysfunction of this system in Parkinson's disease (Redgrave et al., 2010). The loss of automatic control of movement would by necessity force an individual to devote more cognitive resources to execute motor programs associated with routine tasks (e.g. walking), which are automatic in healthy individuals. In consequence, controlled execution of routine motor actions might decrease patients' capacity to flexibly deal with changes in their surrounding environment. Using fMRI studies, it was also suggested that altered STN activations underlie the occurrence of FOG in a subset of PD patients (Moustafa, 2014; Shine, Frank, Moustafa, \& Lewis, 2013). Computational modeling suggested that increased STN activity can impair initiation of motor responses, including gait - and in particular it can induce a type of freezing when subjects experience response conflict (Frank, Samanta, Moustafa, \& Sherman, 2007 \& Sherman, 2007). One computational model suggested a possible link between serotonin deficiency and FOG, in addition to PD-related dopamine deficits (Muralidharan, Balasubramani, Chakravarthy, Lewis, \& Moustafa, 2014 Lewis, \& Moustafa, 2014).

In contrast to general gait deficits, FOG is also commonly exacerbated when individuals are required to perform stressful tasks (Ehgoetz Martens, Ellard, \& Almeida, 2014; A. Lieberman, 2006) or are required to navigate in complex spatial environments (Almeida \& Lebold, 2010). One may argue therefore, that rather than reflecting a general impairment of cognition, freezing may be due to an inability to effectively manage response 
conflict, irrespective of the domain in which it occurs (Shine et al., 2013; Vandenbossche et al., 2012).

\section{Effects of dopaminergic medications and DBS}

The administration of dopaminergic medications leads to a general improvement in gait abnormalities (Bohnen, Albin, Muller, \& Chou, 2011), though FOG cannot be completely ameliorated with dopaminergic replacement (Nutt et al., 2011; Shine, Naismith, \& Lewis, 2011). For example, a study has reported that FOG in some PD patients did not respond well to levodopa (Ferraye et al., 2013). In addition, there are currently significant limitations associated with long-term dopaminergic therapy in general, as it often leaded to side effects, such as dyskinesias. Similar effects have been seen with DBS surgery (Bohnen et al., 2011), however there remains contention regarding the best stimulation target for effective treatment of freezing (Alam, Schwabe, \& Krauss, 2011; Vercruysse et al., 2014). For instance, a case study has reported that DBS to the pedunculopontine nucleus (PPN) could effectively remediate FOG in a patient with PD (Wilcox et al., 2011), suggesting a key role for the PPN in gait control.

\section{c- Handwriting deficits: Micrographia}

\section{Clinical features}

A recent study has suggested that handwriting can be used as an early detection tool for PD (Rosenblum, Samuel, Zlotnik, Erikh, \& Schlesinger, 2013). PD patients typically exhibit a diminutive form of handwriting known as micrographia. In an early study of micrographia, McLennan and colleagues found that micrographia is present in a large proportion of PD patients and is dissociable from other PD motor symptoms including tremor and rigidity (McLennan, Nakano, Tyler, \& Schwab, 1972). Although altered handwriting in 
PD patients has been recognized for a long time, empirical studies of PD handwriting features have begun to gain prominence only since the 1990s, as discussed by Bidet-Ildei and colleagues (Bidet-Ildei, Pollak, Kandel, Fraix, \& Orliaguet, 2011). In addition to micrographia, handwriting in PD is characterized by a jagged contour and sharp fluctuations in velocity and acceleration profiles (Teulings, Contreras-Vidal, Stelmach, \& Adler, 2002; Van Gemmert, Teulings, Contreras-Vidal, \& Stelmach, 1999). Aspects of handwriting including stroke size, peak acceleration, stroke duration, ratio between mean and standard deviation of stroke length or duration all have been used for PD diagnostics (Phillips, Bradshaw, Iansek, \& Chiu, 1993; Teulings \& Stelmach, 1991). Compared to healthy controls, PD patients were found to exhibit increased movement time, reduced maximum and minimum values of magnitude of pen velocity and more velocity inversions (Tucha et al., 2006). In a study by van Gemmert and colleagues (Van Gemmert, Adler, \& Stelmach, 2003), PD patients were asked to copy repetitive '1ll' patterns of different sizes. It was found that patients undershot the target if the target size was greater than $1.5 \mathrm{~cm}$, thereby indicating that letter size reduction effect is characterized by a threshold, becoming significant at a critical target size.

\section{Neural substrates}

Since handwriting requires integration of cognitive, linguistic, perceptual and motor functions, and is naturally subserved by an extensive brain network, impaired handwriting is observed in a variety of neurological conditions. There is evidence of the involvement of Broca's area, classically known for its role in speech production, in handwriting generation (Hillis et al., 2002). Other brain areas, including the dorsolateral and medial premotor cortex, are involved in handwriting (Beeson et al., 2003). Future research should investigate the activation of these brain regions in PD patients while conducting a handwriting task. 
Repetitive transcranial magnetic stimulation of the supplementary cortex has been shown to improve handwriting in PD patients (Randhawa, Farley, \& Boyd, 2013). Since handwriting involves processing of space through visual and somatosensory modalities, intraparietal sulcus and superior parietal lobule can also be expected to support handwriting. In addition to sensory motor cortical areas, prefrontal areas typically associated with planning and execution such as the left inferior and dorsolateral prefrontal cortex also influence handwriting (Beeson et al., 2003). Through computational modeling, reducing dopamine levels in the basal ganglia, the substantia nigra and the globus pallidus external (GPe) pathways also led to reduction of the size of the letters written by PD patients (Gangadhar, Joseph, \& Chakravarthy, 2008; for a review see Helie, Chakravarthy, \& Moustafa, 2013). As we have seen, due to the complex nature of handwriting, impairment of a number of regions could affect handwriting. It remains to be clarified which brain areas show abnormal activations during handwriting in PD patients, as compared to healthy controls.

\section{Effects of dopamine medications and DBS}

The clinical value of assessing handwriting in PD is not only provision of a sensitive marker of early PD onset, but its response to dopaminergic medication also forms the basis of a rapid, quantitative assessment of pharmacotherapy effect. Lange and colleagues reported progressive degeneration of handwriting as PD patients were withdrawn from their normal dopamine medications (Lange et al., 2006). Using computational analysis of PD handwriting, Eichhorn and colleagues demonstrated that certain sensitive indices derived from handwriting showed rapid improvement in PD patients on apomorphine (Eichhorn et al., 1996). However, these positive changes were not always observed in patients with levodopa-unresponsive Parkinsonism. For example, Poluha and colleagues found that levodopa ameliorated the 
speed of handwriting, but not the size of written letters (Poluha, Teulings, \& Brookshire, 1998).

There are few studies investigating the effects of DBS to STN, GPi or other brain targets on handwriting. One study involving patients with advanced PD undergoing highfrequency STN DBS revealed that stimulation improved handwriting quality; there was a significant increase in mean vertical stroke length, speed of writing and smoothness of contour (Siebner et al., 1999). However, another study found that STN DBS had only moderate effects on handwriting in PD patients (Bidet-Ildei et al., 2011). Future studies should investigate whether the exact positioning of the DBS electrodes in the STN as well as the DBS stimulation parameters might have differential effects on handwriting, as different STN regions impact different brain structures, and may thus impact handwriting differently. Further, future studies should investigate if handwriting correlates with other motor processes (including gait, speech, and hand motor control) and should elucidate the neural substrates of handwriting. fMRI studies in healthy populations have shown the involvement of prefrontal and parietal cortices in handwriting; however, although these brain areas are known to be affected in PD, yet it is not known whether their deficiency contributes to impaired handwriting in the disease.

\section{d- Precision grip deficits}

\section{Clinical features}

Precision grip (PG) is a grip formed by the index finger and thumb to hold a small object (Napier, 1956). This form of grip, unique to old world monkeys and great apes (Jones \& Lederman, 2006), enables them to make (Marzke, 1997; Susman, 1998) and dexterously use tools (Ambrose, 2001; Jones \& Lederman, 2006; Moyà-Solà, Köhler, \& Rook, 1999; Young, 2003). PG dexterous manipulation is included in studies that examine motor integration (Müller \& Dichgans, 1994). PG is also used as a tool for assessment of loss of 
functionality in various disorders, including PD (Fellows, Noth, \& Schwarz, 1998; Ingvarsson, Gordon, \& Forssberg, 1997).

In a typical PG task, participants are required to use precision grip and lift an object to a designated height (Eliasson, Forssberg, Hung, \& Gordon, 2006; Fagergren, Ekeberg, \& Forssberg, 2003; Johansson, 1998; Johansson \& Cole, 1994; Johansson, Hager, \& Riso, 1992; Johansson, Riso, Hager, \& Backstrom, 1992; Johansson \& Westling, 1984, 1988a, 1988b; Ulloa, 2004). The two primary forces generated by the fingers are load force (which lifts the fingers) and grip force (which couples the fingers and the object). An optimal load force is required to lift the object to the desired height without overshooting and optimal grip force is crucial for coupling the fingers to object, minimizing fatigue and preventing damage to the object. For a constant object weight, the grip force profile shows a rapid increase in grip force from initial (zero grip force) to reach a peak and then gradual settling to a static value (Johansson \& Westling, 1984). The components of the grip force profile are rate of grip force development, peak grip force, static grip force and safety margin.

It has been observed that PD patients were able to scale the forces for changes in object weight and object size (Gordon, Ingvarsson, \& Forssberg, 1997). Interestingly, when PD patients were asked to drop a load in the plate attached to the manipulandum they were holding, a preparatory increase in grip force was also observed. Thus, PD patients were able to engage in anticipatory control of the force generated in a familiar task (Gordon et al., 1997). Another study found that PD patients employed a higher and static grip force than controls when lifting objects which were either weighted similarly or differently than the previous trials (Fellows et al., 1998).

\section{Neural substrates}


Many brain regions involved in motor control are recruited during grip force generation. The sensory information about the muscle length, tendon tension, joint configurations and changes in configurations are sent to the spinal cord. This information is then received by the cerebellum and thalamus. The cerebellum is involved in temporal coordination of multi-joint movement sequences (Fellows, Ernst, Schwarz, Töpper, \& Noth, 2001). Damage to dentate nucleus or afferent input effects the sensorimotor processing which eventually leads to mistiming of grip force generation (Fellows et al., 2001). A dedicated region in the thalamus projects to the primary somatic sensory cortex (S-I) (Strick, 1976). S-I projects to secondary somatic sensory cortex (S-II) and posterior parietal cortex (BA5 and BA7). The primary motor cortex (involved in control of movement execution) and premotor areas (involved in motor preparation through sensory and motor planning) receive inputs from regions BA5 and BA7 (Kandel, Schwartz, \& Jessell, 2000). A study involving transient virtual lesions found that lesions in left or right ventral premotor areas impaired the correct finger positioning on the object; contralateral ventral premotor lesion impaired sequential recruitment; and left dorsal premotor area lesion affected grasping and lifting phases (Davare, Andres, Cosnard, Thonnard, \& Olivier, 2006). Hence, the dorsal and ventral premotor areas seem to control different phases of the precision grip (Davare et al., 2006).

In a PG task, different aspects of motor tasks are controlled by different areas of basal ganglia. The basal ganglia are involved both in the PG planning and the grip force modulation. A task requiring constant or variable grip force amplitude production activated the caudate, the putamen, the GPe, the GPi and the STN (Vaillancourt, Yu, Mayka, \& Corcos, 2007) but the selection of the grip force was limited to the anterior basal ganglia (caudate nucleus, anterior putamen and GPe). Another study, which involved four tasks that required a switching between two force amplitude levels and relative timing, also showed that the anterior basal ganglia were highly active for tasks requiring switching between two force 
amplitude levels but not for the task with varied timing and constant force amplitude (Pope, Wing, Praamstra, \& Miall, 2005). Hence, these areas are involved in initial grip force selection. Initial grip force generation is an entirely feed-forward process which is shaped by previous experience (Gordon, Westling, Cole, \& Johansson, 1993; Johansson, Riso, et al., 1992). Wasson and colleagues demonstrated that the activation of putamen and caudate reflected the predictability of the grip force (Wasson, Prodoehl, Yu, Corcos, \& Vaillancourt, 2007). Boecker and colleagues (Boecker et al., 2005) provided further insight about the role of the anterior basal ganglia in planning of predictability in a PG lift task. In a visually guided PG task, it was shown that activity of the STN and the GPi scaled with the rate of change of force production whereas GPe and putamen activity increased with the duration (Janey Prodoehl, Yu, Wasson, Corcos, \& Vaillancourt, 2008; Vaillancourt, Mayka, Thulborn, \& Corcos, 2004). A fMRI study has revealed that contralateral and ipsilateral fronto-parietal areas and sub-cortical motor structures were concurrently working in a PG lift task (H. H. Ehrsson, Fagergren, Johansson, \& Forssberg, 2003). A PET study demonstrated that the contralateral posterior putamen and the thalamus were activated when lifting objects with different weights (J. Prodoehl, Corcos, \& Vaillancourt, 2009). Further investigation of the basal ganglia nuclei involved in grip force amplitude production revealed that the GPi and the STN was involved in amplitude scaling whereas the GPe, the putamen and the caudate did not show an increase (Spraker, Yu, Corcos, \& Vaillancourt, 2007). A fMRI study on PG in healthy individuals reported increased activity in visual cortical areas, supplementary motor cortex, parietal cortex, and fusiform gyrus (Neely, Coombes, Planetta, \& Vaillancourt, 2013). In summary, the basal ganglia are involved in planning and modulation of grip force. Anterior basal ganglia (caudate, anterior putamen, and GPe) plan the initial grip force production, whereas posterior basal ganglia (posterior putamen, GPi and STN) modulate the grip force on a dynamical basis. Additionally, multiple cortical areas are also activated during 
PG tasks. With multiple areas employed in PG, further research should investigate how this task is impaired in PD patients. We argue that this may provide a sensitive tool for measuring the progression of the disease.

\section{Effects of dopamine medications and DBS}

PD patients on medications demonstrated a slow grip force development, higher grip onset to lift latency, higher time for the peak grip force generation, larger lift durations and lower object heights while handling objects with different weights (Fellows et al., 1998). Similar findings were also reported in de novo PD patients who demonstrated higher grip to lift latency, higher time for the peak grip force generation, higher peak grip force and higher static grip force (S. J. Fellows \& Noth, 2004). In a study by Ingvarsson and colleagues, the grip force generated by controls and PD patients in the on and off medication states for silk and sand paper surface conditions was compared. The static grip force generated by PD patients was comparable to controls when using sandpaper as the surface, independently of the patients' medication status (Ingvarsson et al., 1997). However, static grip forces generated by PD patients in the ON condition for silk surfaces showed higher static grip forces and safety margin than controls. Interestingly, PD patients tested OFF medication showed higher variance both than controls and PD patients ON medication (Ingvarsson et al., 1997).

The reasons for such variations in peak and static grip force by PD patients (both on and off medication) were investigated by Wenzelburger and colleagues (Wenzelburger et al., 2002). They examined the influence of levodopa induced dyskinesia (LID) on precision grip performance. PD patients with LID (PD+LID) showed higher peak and static grip force, as compared to PD patients without LID (PD-LID) and controls. ON medication patients in PD+LID had higher peak and greater static grip force than OFF medication PD+LID patients. Higher grip force development was present only in the PD+LID group and dopamine 
medications further increased the grip forces developed (Wenzelburger et al., 2002). In an attempt to understand the altered grip forces in PD Gupta and colleagues (Gupta, Balasubramani, \& Chakravarthy, 2013) proposed a computational model of risk-based decision making during PG control in controls and PD patients OFF and ON medication. The model was able to replicate experimental findings, thereby providing valuable insights about the decision making dynamics involved in grip force selection (Gupta et al., 2013).

STN DBS induced a significant improvement in lifting velocity and grip force production rate (Fellows et al., 2006). By contrast, PD patients (who were generating higher peak grip force and static grip force with DBS off) had a further increase in peak grip force and static grip force with DBS switched on (S. J. Fellows et al., 2006). This may indicate that force development in precision grip is highly dependent on the integrity of the basal ganglia. STN DBS at present falls short of alleviating all the motor symptoms in a precision grip task.

The PG task is a very powerful and sensitive (due to the fine finger force generation requirement) tool for understanding impairment of motor performance in PD. Previous studies have characterized motor performance, resting tremor (Mansur et al., 2007; Rigas, Tzallas, Tsalikakis, Konitsiotis, \& Fotiadis, 2009; Salarian \& al., 2007), rigidity (Fung, Burne, \& Morris, 2000; Patrick, Denington, Gauthier, Gillard, \& Prochazka, 2001; Prochazka et al., 1997; Sepehri et al., 2007) and bradykinesia (Allen \& al., 2007; Dunnewold, Jacobi, \& van Hilten, 1997; Kim et al., 2011; Veltink \& al., 1995), individually and in combination (Ghika et al., 1993; Niazmand \& al., 2011; Papapetropoulos et al., 2010; Veltink \& al., 1995), but did not explore the temporal evolution of motor performance changes in the short term due to medication and in the long term due to disease progression in PG. Therefore, future studies on PG in PD should be directed towards quantitative estimation of motor symptoms (specifically akinesia, bradykinesia and tremor) to understand the changes in individual 
symptoms with disease progression and starting medication. This might open new avenues for symptom-specific drug adjustments or DBS for alleviating PD symptoms.

\section{e- $\quad$ Speech problems in Parkinson's disease}

\section{Clinical features}

Most PD patients developed speech and voice disorders at some point during their illness (Ho, Iansek, Marigliani, Bradshaw, \& Gates, 1998). Speech production was found to correlate with other motor symptoms in PD, including akinesia (Skodda et al., 2011). Along these lines, speech stuttering was also found to correlate with FOG in PD patients (Morgante et al., 2013; Park et al., 2014). Interestingly, it was also found that bradykinesia was related to speech disorders in PD (Robbins, Logemann, \& Kirshner, 1986). Speech disturbances have also been shown to be more common in PD patients who had a high occurrence of FOG (Park et al., 2014). The correlation of gait and speech symptoms could be due to the fact that both motor processes require the coordination of different motor effectors (e.g., lip and jaw in speech control and both legs in gait).

Speech in PD is often hypophonic (i.e. hypokinetic, soft speech), monotonic (i.e. speech quality tends to be soft, hoarse, and monotonous) and/or festinating (excessively rapid, soft, poorly intelligible speech) (Jankovic, 2008). Dysarthria, that is, slurred, slow, and almost incomprehensible speech, is also common in PD. Few studies have focused on the complex movements involved in the articulation of speech, while the majority of the studies investigating hypokinetic dysarthria have focused on perceptual measures. One study investigated sequencing of lip and jaw movements while speaking, and showed a decreased coordination across these articulators in PD patients (Connor, Abbs, Cole, \& Gracco, 1989). Another study found altered movements of lips and jaws in PD patients compared to controls (Forrest, Weismer, \& Turner, 1989). 
Until recently, the only outcome on which studies have focused was speech production. However, motor function also exerts a great influence on speech function, which gave rise to a new motor interaction model (Levelt, Roelofs, \& Meyer, 1999), which suggests that in addition to the goal of the spoken statements, the syntactic structure should be taken into consideration (Kleinow \& Smith, 2006). Maner and colleagues (Maner, Smith, \& Grayson, 2000) have shown that speech motor planning, execution, or both were affected by processes often considered relatively remote from the motor output stage. Several studies have indicated that the greater the linguistic demand, the more disruptions there will be in the speech pathway (Maner et al., 2000). In addition, adults who stutter had more variation in their articulation movement patterns. Moreover, syntactic complexity and higher disfluency differed between normal children and children who stutter (Silverman \& Ratner, 1997). These studies support the conjecture that higher order processes influence speech motor control even in adults and children without any neurological deficits (Kleinow \& Smith, 2000); future studies should investigate whether and how such processes impact speech production in $\mathrm{PD}$.

Illes, Metter, Hanson, and Iritani (1988) and Cummings and colleagues (1988) collected speech samples from PD patients and in these samples found reduced utterance length and syntactic complexity, as compared with controls. In addition, PD patients produced a smaller proportion of grammatically intact sentences. Moreover, Grossman and colleagues (Grossman et al., 1991) found that PD patients showed impairment answering probes paired with complex sentences with central or terminal clauses (C. Lee, Grossman, Morris, Stern, \& Hurtig, 2003).

Stuttering has also been reported in PD (Anderson, Hughes, Rothi, Crucian, \& Heilman, 1999). In addition, experimental and computational studies have indicated that stuttering is related to basal ganglia function (Burghaus et al., 2006; Civier, Bullock, Max, \& 
Guenther, 2013). Future work should explore the neural underpinnings of stuttering in PD, and reveal whether the basal ganglia and/or other brain regions are responsible for stuttering in PD. Given previous studies showing correlations between speech and gait (including stuttering and FOG), we predict that stuttering may also be related to cortical dysfunction, besides the impairment of the basal ganglia. Several other issues remain to be clarified, such as the cortical and subcortical substrates of various other aspects of speech, including hypophonia, and whether hypophonia correlate with other motor symptoms in PD, such as micrographia and smaller stride steps.

\section{Neural substrates}

Lieberman and colleagues (P. Lieberman et al., 1992) compared speech behavior in PD and healthy controls. They suggested that speech production and syntactic ability were dependent on basal ganglia pathways. Speech symptoms related to abnormalities of the basal ganglia in PD were found to be somewhat similar to symptoms of a patient who was suffering from Broca's aphasia. Ellfolk and colleagues (Ellfolk et al., 2014) measured the gray matter volume of the caudate nucleus in early onset, non-demented PD patients on levodopa. These patients also performed a phonemic and a semantic fluency test. The results suggested that patients who had lower gray matter volume in their right caudate performed poorer on the phonemic fluency test. However, this pattern absent for the semantic fluency test. The findings from these two studies suggest that areas that are affected by PD also play a role in the cognitive component of speech production. In addition, Azevedo and colleagues suggested that bradykinesia may affect the prosody of the patients' speech (Azevedo, Reis, Souza, \& Cardoso, 2013).

\section{Effects of dopamine medications and DBS}


Although dopamine replacement therapies are effective at treating rigidity and bradykinesia, they can either impair or have no effect on speech disorders (Maillet et al., 2012) or speech performance (Azevedo et al., 2013). This indicate that dopaminergic and non-dopaminergic deficits might contribute to the occurrence of speech disorders in PD. Probably due to the limited understanding of the pathophysiology of speech- and voicerelated symptoms in PD, their medical treatment has been largely ineffective. However, these findings were not supported by a study which found that dopamine treatment did indeed have a positive effect on speech (Rusz et al., 2013). This contradictory finding could be due to the acoustic analysis technique employed by the group, highlighting the importance of the methodology used to assess voice and speech in PD patients. However, the combination of pharmacological and surgical treatment with behavioral speech therapy has been demonstrated to be efficient (Schulz \& Grant, 2000; Spielman et al., 2011). This was supported by several reviews of the literature on the treatment of speech problems in PD patients (Sapir, Ramig, \& Fox, 2011; Trail et al., 2005).

The effect of dopamine medications on speech disorders in PD seem to depend on the kind of medication administered (levodopa vs. dopamine agonists). While some studies reported improvement of speech-voice problems with levodopa (Gallena, Smith, Zeffiro, \& Ludlow, 2001), other studies found that dopamine agonist medications were not effective in the treatment of voice-speech disorders of PD (Goberman, 2005), and may even increase speech dysfluency (Anderson et al., 1999). These effects are possibly due to the overactivation of the direct (Go) pathway of the basal ganglia, as shown by computational modeling studies (Frank, 2005). Several other studies showed that most dopamine medications were ineffective in the treatment of speech problems (Kompoliti, Wang, Goetz, Leurgans, \& Raman, 2000; Larson, 1994; Trail et al., 2005), suggesting that speech problems in PD are not strongly related to dopamine dysfunction (Goberman, 2005). In agreement with 
this, clonazepam (a GABAergic agent) was found to significantly improve some aspects of speech in PD (Biary, Pimental, \& Langenberg, 1988).

Surgical procedures such as DBS (of the thalamus, the pallidum or the STN) and ablative surgeries have shown to be less effective in ameliorating speech problems in PD patients. Some studies showed no improvement and in some cases, even impairment of speech (Borden et al., 2014; B. Wu, Han, Sun, Hu, \& Wang, 2014). Other studies have found some improvement in speech after DBS surgery; however, this improvement is much smaller than that observed for other motor problems. What is more, the improvements have been found to disappear after five years (A. L. Benabid, Chabardes, Mitrofanis, \& Pollak, 2009), and some have reported dysarthria as a major side-effect of DBS (Krack et al., 2003). Biary and colleagues suggest that the spread of voltage from the stimulation target to neighboring areas that mediate sensorimotor control may cause the adverse effect seen on speech (Biary et al., 1988). Other studies have, however, shown an ameliorative effect of STN DBS on dysarthria in PD patients (Pinto, Thobois, et al., 2004). In addition, stimulator settings may affect speech, with high frequencies and amplitude having a detrimental effect on the intelligibility of the speech (Törnqvist et al., 2005). Other studies found that the electrode positioning within the STN had variable effects on speech production (Tripoliti et al., 2011). The effects of STN DBS on stuttering is inconclusive, as some studies reported the impairment (Burghaus et al., 2006; Toft \& Dietrichs, 2011) and others the amelioration of this symptom after the neurosurgical intervention (Walker et al., 2009).

As previously mentioned, since pharmacological or surgical therapies alone appeared to lack the desired effects on speech problems, combining these with behavioral speech therapy is highly recommended even for PD patients who have undergone both therapies (Pinto, Ozsancak, et al., 2004). While there are some studies that have found a positive effect of speech therapies (e.g. Spielman et al., 2011), these studies were limited by small sample 
sizes and methodological flaws, leaving insufficient evidence to support or oppose speech therapy in PD (Herd et al. 2012). However, in their review on the treatments of PD symptoms, Suchowersky and colleagues concluded that speech therapies that are intensive focus on the volume of speech are the most effective (e.g. Lee Silverman Voice Treatment, LSVT LOUD) (Suchowersky et al., 2006).

The majority of PD patients experience speech difficulties during the progression of the disease. While the incidence is high, the effectiveness of DA therapies and surgical intervention is low, and in some cases detrimental to speech. There does appear to be some benefit in combining current medical and surgical treatments with speech therapy. However, currently there is insufficient evidence to support these proposals, prompting further controlled research in this area.

\section{Conclusions}

In this review, we focused on the clinical features and neural substrates of the primary and secondary motor symptoms of PD. The review highlighted that the different motor symptoms of PD are associated with somewhat similar clinical and neural features. For example, the provision of lines have been shown to enhance both handwriting (Oliveira, Gurd, Nixon, Marshall, \& Passingham, 1997) as well as gait (Park et al., 2014), suggesting that perceptual input from external stimuli can enhance motor performance related to different effectors in PD. Further, some brain regions, such as Broca's area that are known to play a role in language production were also shown to be involved in handwriting (Hillis et al., 2002) and gait (Albani et al., 2001), further suggesting common neural substrates for these different motor processes.

In addition, one study has reported a patient with both micrographia and hypophonia (Sekar, Arcelus, \& Palmer, 2010), suggesting that reduced speech volume and smaller 
handwriting may share common neural substrates. Smaller stride length is conceptually similar to reduced speech volume and small letters in handwriting, and has been also reported in PD patients (Lewis, Byblow, \& Walt, 2000; Morris, Iansek, Matyas, \& Summers, 1996). To our knowledge, no study has investigated whether micrographia, hypophonia, and smaller stride length are correlated in PD patients. In addition, motor blocking including stuttering and FOG were found to correlate in PD patients (Morgante et al., 2013), suggesting that the initiation of various motor responses (speech or gait) may share a common neural mechanism.

\begin{tabular}{|c|c|c|c|}
\hline & Medication & DBS & Neural basis \\
\hline $\begin{array}{l}\text { Akinesia \& } \\
\text { Bradykinesia }\end{array}$ & $\begin{array}{l}\text { DA treatment improves } \\
\text { response times } \\
\text { (Vaillancourt, Prodoehl, } \\
\text { Verhagen Metman, Bakay, } \\
\text { \& Corcos, 2004). }\end{array}$ & $\begin{array}{l}\text { Stimulation of the STN } \\
\text { reduced akinesia by } 57 \% \\
\text { (Brown et al., 1999). } \\
\text { Stimulation of the GPi had } \\
\text { mixed results, depending on } \\
\text { the location within the GPi } \\
\text { (Krack et al., 1998). }\end{array}$ & $\begin{array}{l}\text { Decrease of DA activity in the } \\
\text { dorsal striatum (Kish, et al., } \\
\text { 1988) and globus pallidus } \\
\text { (Rajput, et al., 2009) } \\
\text { Under activation of } \\
\text { supplementary motor and } \\
\text { anterior cingulate cortex } \\
\text { (Sabatini et al., 2000) }\end{array}$ \\
\hline Rigidity & $\begin{array}{l}\text { Levodopa reduced rigidity } \\
\text { (Kuhn et al., 2009). This } \\
\text { was related to the } \\
\text { suppression of oscillatory } \\
\text { power in the STN. }\end{array}$ & $\begin{array}{l}\text { Improvement of rigidity in the } \\
\text { left limbs correlated with } \\
\text { increase of glucose metabolism } \\
\text { in the right premotor area in } \\
\text { patients on DBS (Nagaoka et } \\
\text { al., 2007). DBS was found to } \\
\text { ameliorate rigidity when } \\
\text { applied to the bilateral, } \\
\text { contralateral and ipsilateral } \\
\text { STN, although the greatest } \\
\text { improvements were observed } \\
\text { for bilateral stimulation } \\
\text { (Tabbal et al., 2008). }\end{array}$ & $\begin{array}{l}\text { Severity of rigidity correlated } \\
\text { with connectivity between the } \\
\text { cerebellum, the motor, } \\
\text { temporal and occipital cortices, } \\
\text { and the nucleus caudatus in } \\
\text { mild-moderate PD patients } \\
\text { OFF medication. }\end{array}$ \\
\hline Tremor & $\begin{array}{l}\text { DA treatment resulted in a } \\
\text { lower score in the UPDRS } \\
\text { tremor ratings (Elble 2002; } \\
\text { Solida, Ghika, \& } \\
\text { Vingerhoets, 2002). }\end{array}$ & $\begin{array}{l}\text { STN DBS reduced tremor by } \\
65 \% \text { (Schlaier, Hanson et al., } \\
\text { 2014). }\end{array}$ & $\begin{array}{l}\text { Abnormal firing patterns in the } \\
\text { cerebellum (Brittain et al., } \\
\text { 2015) } \\
\text { Increased grey matter } \\
\text { concentration in the Thalamus } \\
\text { (Kassubek, et al., 2002; Probst- } \\
\text { Cousin, et al., 2003) } \\
\text { Imbalance of beta and gamma } \\
\text { oscillations in the subthalamic }\end{array}$ \\
\hline
\end{tabular}




\begin{tabular}{|c|c|c|c|}
\hline & & & $\begin{array}{l}\text { nucleus (Weinberger, et al., } \\
\text { 2009). }\end{array}$ \\
\hline Gait & $\begin{array}{l}\text { Freezing of gait is more } \\
\text { common in the off state of } \\
\text { DA treatment, however it is } \\
\text { also known that DA } \\
\text { treatment can increase FOG } \\
\text { occurrences (Nutt, et } \\
\text { al.,2011). }\end{array}$ & $\begin{array}{l}\text { STN DBS improved freezing } \\
\text { scores on the ADL section of } \\
\text { the UPDRS at } 1 \text { and } 2 \text { years } \\
\text { (Davis et al., 2006). PPN DBS } \\
\text { has shown to be effective when } \\
\text { STN DBS fails to improve } \\
\text { FOG and gait (Bohnen et } \\
\text { al.,2011; Alam et al., 2011). }\end{array}$ & $\begin{array}{l}\text { Dysfunctional circuit between } \\
\text { the putamen and SMA } \\
\text { (Redgrave et al., 2010) } \\
\text { Decreased grey matter in } \\
\text { occipital cortical area } \\
\text { (Tessitore et al. 2012). } \\
\text { Dysfunctional networks } \\
\text { between STN and cortical } \\
\text { areas (Shine, et al., 2013) }\end{array}$ \\
\hline $\begin{array}{l}\text { Problems with } \\
\text { Handwriting }\end{array}$ & $\begin{array}{l}\text { DA meds improves } \\
\text { handwriting in PD patients } \\
\text { (Lange et al., 2006), but not } \\
\text { DA resistant PD patients } \\
\text { (Eichhorn et al. 1996). } \\
\text { Levodopa can improve } \\
\text { speed, but not quality of } \\
\text { handwriting (Poluha et al. } \\
\text { 1998). }\end{array}$ & $\begin{array}{l}\text { STN DBS improves } \\
\text { handwriting speed and } \\
\text { accuracy (Siebner et al., 1999). }\end{array}$ & $\begin{array}{l}\text { Dorsolateral and medial } \\
\text { premotor cortex are active } \\
\text { during the orthographical } \\
\text { retrieval of words (Beeson et } \\
\text { al., 2003), areas that are also } \\
\text { dysfunction in PD patients. } \\
\text { TMS on the supplementary } \\
\text { cortex improves handwriting in } \\
\text { PD patients (Randhawa, et al., } \\
\text { 2013) } \\
\text { Reduced DA levels in the BG, } \\
\text { SN and GPe pathways also } \\
\text { leads to a reduction in letter } \\
\text { size by PD patients } \\
\text { (Gangadhar, et al., 2008). }\end{array}$ \\
\hline $\begin{array}{l}\text { Deficits in } \\
\text { Force } \\
\text { generation } \\
\text { and Precision } \\
\text { grip }\end{array}$ & $\begin{array}{l}\text { DA treatment increases grip } \\
\text { force and reduces force } \\
\text { oscillations observed during } \\
\text { OFF periods (Ingvarsson et } \\
\text { al., 1997). }\end{array}$ & $\begin{array}{l}\text { STN DBS decreases grip } \\
\text { initiation, however excessive } \\
\text { forced used is also increased } \\
\text { (Fellows et al. 2006). }\end{array}$ & $\begin{array}{l}\text { BG are involved in both the PG } \\
\text { planning and grip force } \\
\text { modulation (Vaillancourt, et } \\
\text { al., 2007) } \\
\text { High activation in visual } \\
\text { cortical areas, supplementary } \\
\text { motor cortex, parietal cortex, } \\
\text { and fusiform gyrus (Neely, et } \\
\text { al., 2013). All of these areas } \\
\text { are dysfunctional in PD } \\
\text { patients. }\end{array}$ \\
\hline $\begin{array}{l}\text { Speech } \\
\text { problems }\end{array}$ & $\begin{array}{l}\text { DA treatment does not have } \\
\text { an effect on prosody, } \\
\text { however it improves speech } \\
\text { speed (Azevedo et al., } \\
\text { 2013). DA treatment } \\
\text { improved articulation, pitch } \\
\text { variance, intensity and } \\
\text { overall voice quality (Rusz } \\
\text { et al. 2013). DA treatment } \\
\text { increases speech } \\
\text { dysfluencies (Anderson et } \\
\text { al.,1999). DA treatment did } \\
\text { not improve speech } \\
\text { (Kompoliti et al., 2000). } \\
\text { ACh treatment has little } \\
\text { effect on speech (Schulz et } \\
\text { al., 2000), and GABA }\end{array}$ & $\begin{array}{l}\text { STN DBS improves the } \\
\text { effectiveness of speech therapy } \\
\text { (Spielman et al., 2011). STN } \\
\text { DBS can have an adverse } \\
\text { effect on speech fluency; } \\
\text { however this disappears after } 6 \\
\text { months (Borden et al. 2014; } \\
\text { Wu et al., 2014). }\end{array}$ & $\begin{array}{l}\text { Production and syntactic ability } \\
\text { are dependent on basal ganglia } \\
\text { pathways (Lieberman et al., } \\
\text { 1992). } \\
\text { PD patients with low grey } \\
\text { matter volume in the right } \\
\text { caudate had poorer phonemic } \\
\text { fluency (Ellfolk et al., 2014) }\end{array}$ \\
\hline
\end{tabular}



al.,1988).

Table 1. Summary of the neural substrates and therapeutic effects for the main motor

symptoms of PD. DA = dopamine $;$ STN = subthalamic nucleus; $D B S=$ deep brain

stimulation; $B G=$ basal ganglia $;$ SMA = Supplementary motor area $;$ SN = substantia nigra;

$G P i=$ globus pallidus internal $;$ GPe $=$ globus pallidus external $;$ UPDRS $=$ Unified

Parkinson's Disease Rating Scale; $P P N=$ the pedunculopontine nucleus; $F O G=$ freezing of gait $; A D L=$ Activities of Daily Living; $T M S=$ transcranial magnetic stimulation $; G A B A=$ gamma-aminobutyric acid.

Table 1 summarizes the neural substrates and the therapeutic effects of medication and DBS on motor symptoms of PD. The finding that dopaminergic medications are not very effective at managing complex motor symptoms of PD, such as gait, handwriting and speech problems, suggests that striatal dopamine depletion is not the sole cause of these symptoms; as can be seen in Table 1, there is convincing evidence from experimental studies that different cortical areas play a key role in these complex motor processes, and this may explain why medications that balance striatal function may not be effective for these motor symptoms. This is in contrast to the effects of dopaminergic medications on the cardinal symptoms of PD (akinesia, bradykinesia, tremor and rigidity), which seem to improve by an increase in striatal dopamine levels. Further, the findings that dopamine medications can impair some motor processes, such as gait and speech (see summary of results in Table 1) may be explained by the dopamine overdose hypothesis (Cools, Barker, Sahakian, \& Robbins, 2001; Vaillancourt, Schonfeld, Kwak, Bohnen, \& Seidler, 2013), which suggests that dopamine medications can overflood brain regions that are intact at a given point of the disease course, and consequently impair the associated motor functions. 
Thus, here we propose that a simple systems-level framework (Figure 1 above) can explain some of the more complex motor symptoms of PD (see Figure 1). In this framework, different brain regions subserve different functions: (a) the basal ganglia supports action selection (Gurney, Prescott, \& Redgrave, 2001), (b) the cerebellum supports motor coordination and timing (Ivry, Spencer, Zelaznik, \& Diedrichsen, 2002; Kashiwabuchi et al., 1995; Schlerf, Spencer, Zelaznik, \& Ivry, 2007; Shibuki et al., 1996; Spencer \& Ivry, 2005; Spencer, Ivry, \& Zelaznik, 2005), and (c) motor cortical areas support integrating perceptual input as well as motor planning and sequencing (Dagher, Owen, Boecker, \& Brooks, 1999). We suggest that the various motor symptoms discussed in this review all demand action selection, motor coordination and integration, and sensorimotor integration and motor planning, but to a different extent. Moreover, it should be kept in mind that the above outlined functions supporting movement can be divided into further subcomponents; for example, conceptually different (motor) sequencing has been suggested to occur in Broca's area (Udden \& Bahlmann, 2012) and in the premotor area and the SMA (Halsband \& Lange, 2006). In addition, different portions of the striatum (i.e. the dorsomedial, the dorsolateral and the ventral) have been suggested to make different contributions to learning and action selection (see Cools, 2006; Yin \& Knowlton, 2006). It remains to be clarified by future research how more detailed models of motor sequencing and action selection can account for the various motor symptoms in PD.

Importantly, it is argued that the production of motor responses occur at different stages, including the integration of perceptual input and selection of response. Although different motor functions (e.g., gait and handwriting) rely on these processes (as reported above), they are likely to differ on the motor execution mechanism (i.e, different nuclei in the brain control saccades, leg, and hand movement). Future work should focus on investigating the basic brain mechanisms of elementary motor processes so that we can develop an 
understanding of how PD and associated therapies impact the different motor symptoms. Future neurocomputational modeling studies of action selection, sequencing, and coordination and timing of motor processes, as well as the investigation of the role of the basal ganglia, cortex, cerebellum, dopamine, and other brain neurotransmitters in mediating these fundamental motor processes will enhance our understanding of the motor symptoms of PD. Future neuroimaging work should improve upon existing techniques or develop novel techniques to investigate non-dopaminergic systems in PD, as increasing evidence suggests their involvement in most motor symptoms in PD.

Here, we argue that our reductionist approach may be able to explain (a) why dopamine medication and STN DBS may be effective for some motor processes and not others, and (b) why there are correlations among different motor processes, such as gait, speech, and hand movement (as discussed in the introduction). By providing a unified framework, future studies can then attempt to simultaneously find common treatments for the different motor symptoms in PD, rather than approaching individual motor impairments separately. Based on the unified framework proposed here, it is likely that treatments that target different cortical regions may improve complex motor processes such as gait, handwriting, and speech impairment in PD.

In sum, our review shows that many of the motor symptoms in PD rely on overlapping neural regions. Figure 1 depicts the offered unified framework, in which each motor symptom in PD can be potentially explained by a combination of low-level motor processes, such as action selection, motor coordination, and motor sequencing.

\section{References}


Aarsland, D., Andersen, K., Larsen, J. P., Lolk, A., \& Kragh-Sorensen, P. (2003). Prevalence and characteristics of dementia in Parkinson disease: an 8-year prospective study. Arch Neurol, 60(3), 387-392.

Alam, M., Schwabe, K., \& Krauss, J. K. (2011). The pedunculopontine nucleus area: critical evaluation of interspecies differences relevant for its use as a target for deep brain stimulation. Brain, 134(Pt 1), 11-23.

Albani, G., Kunig, G., Soelch, C. M., Mauro, A., Priano, L., Martignoni, E., et al. (2001). The role of language areas in motor control dysfunction in Parkinson's disease. Neurol Sci, 22(1), 43-44.

Albin, R. L., Young, A. B., \& Penney, J. B. (1989). The functional anatomy of basal ganglia disorders. Trends Neurosci, 12(10), 366-375.

Allen, D., \& al., e. (2007). On the use of low-cost computer peripherals for the assessment of motor dysfunction in Parkinson's disease-quantification of bradykinesia using target tracking tasks. Neural Systems and Rehabilitation Engineering, IEEE Transactions on, 15(2), 286-294.

Almeida, Q. J., \& Lebold, C. A. (2010). Freezing of gait in Parkinson's disease: a perceptual cause for a motor impairment? J Neurol Neurosurg Psychiatry, 81(5), 513-518.

Ambrose, S. H. (2001). Paleolithic technology and human evolution. Science, 291(5509), 1748-1753.

Anderson, J. M., Hughes, J. D., Rothi, L. J., Crucian, G. P., \& Heilman, K. M. (1999). Developmental stuttering and Parkinson's disease: the effects of levodopa treatment. J Neurol Neurosurg Psychiatry, 66(6), 776-778.

Azevedo, L. L. d., Reis, C. A. d. C., Souza, I. S. d., \& Cardoso, F. E. C. (2013). Prosody and levodopa in Parkinson's disease. Arq Neuropsiquiatr, 71(11), 835.

Baradaran, N., Tan, S. N., Liu, A., Ashoori, A., Palmer, S. J., Wang, Z. J., et al. (2013). Parkinson's disease rigidity: relation to brain connectivity and motor performance. Front Neurol, 4, 67.

Bartels, A. L., Balash, Y., Gurevich, T., Schaafsma, J. D., Hausdorff, J. M., \& Giladi, N. (2003). Relationship between freezing of gait (FOG) and other features of Parkinson's: FOG is not correlated with bradykinesia. J Clin Neurosci, 10(5), 584-588.

Beeson, P., Rapcsak, S., Plante, E., Chargualaf, J., Chung, A., Johnson, S., et al. (2003). The neural substrates of writing: A functional magnetic resonance imaging study. Aphasiology, 17(6-7), 647-665.

Benabid, Pollak, P., Gao, D., Hoffmann, D., Limousin, P., Gay, E., et al. (1996). Chronic electrical stimulation of the ventralis intermedius nucleus of the thalamus as a treatment of movement disorders. J Neurosurg, 84(2), 203-214.

Benabid, A. L., Chabardes, S., Mitrofanis, J., \& Pollak, P. (2009). Deep brain stimulation of the subthalamic nucleus for the treatment of Parkinson's disease. The Lancet. Neurology, 8(1), 67-81.

Benamer, H. T., Oertel, W. H., Patterson, J., Hadley, D. M., Pogarell, O., Hoffken, H., et al. (2003). Prospective study of presynaptic dopaminergic imaging in patients with mild parkinsonism and tremor disorders: part 1. Baseline and 3-month observations. Mov Disord, 18(9), 977984.

Benamer, H. T., Patterson, J., Wyper, D. J., Hadley, D. M., Macphee, G. J., \& Grosset, D. G. (2000). Correlation of Parkinson's disease severity and duration with 123I-FP-CIT SPECT striatal uptake. Mov Disord, 15(4), 692-698.

Benedetti, F., Colloca, L., Torre, E., Lanotte, M., Melcarne, A., Pesare, M., et al. (2004). Placeboresponsive Parkinson patients show decreased activity in single neurons of subthalamic nucleus. Nat Neurosci, 7(6), 587-588.

Berardelli, A., Rothwell, J. C., Thompson, P. D., \& Hallett, M. (2001). Pathophysiology of bradykinesia in Parkinson's disease. Brain, 124(Pt 11), 2131-2146.

Berardelli, A., Sabra, A. F., \& Hallett, M. (1983). Physiological mechanisms of rigidity in Parkinson's disease. J Neurol Neurosurg Psychiatry, 46(1), 45-53. 
Bhidayasiri, R. (2005). Differential diagnosis of common tremor syndromes. Postgrad Med J, 81(962), 756-762.

Biary, N., Pimental, P. A., \& Langenberg, P. W. (1988). A double-blind trial of clonazepam in the treatment of parkinsonian dysarthria. Neurology, 38(2), 255-258.

Bidet-Ildei, C., Pollak, P., Kandel, S., Fraix, V., \& Orliaguet, J. P. (2011). Handwriting in patients with Parkinson disease: effect of L-dopa and stimulation of the sub-thalamic nucleus on motor anticipation. Hum Mov Sci, 30(4), 783-791.

Boecker, H., Lee, A., Mühlau, M., Ceballos-Baumann, A., Ritzl, A., Spilker, M., et al. (2005). Force level independent representations of predictive grip force-load force coupling: a PET activation study. Neuroimage, 25(1), 243-252.

Bohnen, N. I., Albin, R. L., Muller, M. L., \& Chou, K. (2011). Advances in Therapeutic Options for Gait and Balance in Parkinson's Disease. US Neurol, 7(2), 100-108.

Bohnen, N. I., Frey, K. A., Studenski, S., Kotagal, V., Koeppe, R. A., Scott, P. J., et al. (2013). Gait speed in Parkinson disease correlates with cholinergic degeneration. Neurology, 81(18), 16111616.

Borden, A., Wallon, D., Lefaucheur, R., Derrey, S., Fetter, D., Verin, M., et al. (2014). Does early verbal fluency decline after STN implantation predict long-term cognitive outcome after STN-DBS in Parkinson's disease? J Neurol Sci.

Brittain, J. S., Cagnan, H., Mehta, A. R., Saifee, T. A., Edwards, M. J., \& Brown, P. (2015). Distinguishing the central drive to tremor in Parkinson's disease and essential tremor. $J$ Neurosci, 35(2), 795-806.

Brown, R. G., Dowsey, P. L., Brown, P., Jahanshahi, M., Pollak, P., Benabid, A. L., et al. (1999). Impact of deep brain stimulation on upper limb akinesia in Parkinson's disease. Ann Neurol, 45(4), 473-488.

Burghaus, L., Hilker, R., Thiel, A., Galldiks, N., Lehnhardt, F. G., Zaro-Weber, O., et al. (2006). Deep brain stimulation of the subthalamic nucleus reversibly deteriorates stuttering in advanced Parkinson's disease. J Neural Transm, 113(5), 625-631.

Cantiniaux, S., Vaugoyeau, M., Robert, D., Horrelou-Pitek, C., Mancini, J., Witjas, T., et al. (2010). Comparative analysis of gait and speech in Parkinson's disease: hypokinetic or dysrhythmic disorders? J Neurol Neurosurg Psychiatry, 81(2), 177-184.

Civier, O., Bullock, D., Max, L., \& Guenther, F. H. (2013). Computational modeling of stuttering caused by impairments in a basal ganglia thalamo-cortical circuit involved in syllable selection and initiation. Brain Lang, 126(3), 263-278.

Collins, A. G., \& Frank, M. J. (2014). Opponent actor learning (OpAL): modeling interactive effects of striatal dopamine on reinforcement learning and choice incentive. Psychol Rev, 121(3), 337366.

Connor, N. P., Abbs, J. H., Cole, K. J., \& Gracco, V. L. (1989). Parkinsonian deficits in serial multiarticulate movements for speech. Brain, 112 ( Pt 4), 997-1009.

Cools, R. (2006). Dopaminergic modulation of cognitive function-implications for L-DOPA treatment in Parkinson's disease. Neurosci Biobehav Rev, 30(1), 1-23.

Cools, R., Barker, R. A., Sahakian, B. J., \& Robbins, T. W. (2001). Enhanced or impaired cognitive function in Parkinson's disease as a function of dopaminergic medication and task demands. Cereberal Cortex, 11(12), 1136-1143.

Crouse, J. J., Phillips, J. R., Jahanshahi, M., \& Moustafa, A. A. (2016). Postural instability and falls in Parkinson's disease. Rev Neurosci.

Cummings, J. L., Darkins, A., Mendez, M., Hill, M. A., \& Benson, D. F. (1988). Alzheimer's disease and Parkinson's disease: comparison of speech and language alterations. Neurology, 38(5), 680684. 
Dagher, A., Owen, A. M., Boecker, H., \& Brooks, D. J. (1999). Mapping the network for planning: a correlational PET activation study with the Tower of London task. Brain, 122 ( Pt 10), 19731987.

Davare, M., Andres, M., Cosnard, G., Thonnard, J.-L., \& Olivier, E. (2006). Dissociating the role of ventral and dorsal premotor cortex in precision grasping. The Journal of neuroscience, 26(8), 2260-2268.

Dunnewold, R. J., Jacobi, C. E., \& van Hilten, J. J. (1997). Quantitative assessment of bradykinesia in patients with Parkinson's disease. J Neurosci Methods, 74(1), 107-112.

Eggers, C., Kahraman, D., Fink, G. R., Schmidt, M., \& Timmermann, L. (2011). Akinetic-rigid and tremor-dominant Parkinson's disease patients show different patterns of FP-CIT single photon emission computed tomography. Mov Disord, 26(3), 416-423.

Eggers, C., Pedrosa, D. J., Kahraman, D., Maier, F., Lewis, C. J., Fink, G. R., et al. (2012). Parkinson subtypes progress differently in clinical course and imaging pattern. PLoS One, 7(10), e46813.

Ehgoetz Martens, K. A., Ellard, C. G., \& Almeida, Q. J. (2014). Does anxiety cause freezing of gait in Parkinson's disease? PLoS One, 9(9), e106561.

Ehrsson, Naito, E., Geyer, S., Amunts, K., Zilles, K., Forssberg, H., et al. (2000). Simultaneous movements of upper and lower limbs are coordinated by motor representations that are shared by both limbs: a PET study. Eur J Neurosci, 12(9), 3385-3398.

Ehrsson, H. H., Fagergren, A., Johansson, R. S., \& Forssberg, H. (2003). Evidence for the involvement of the posterior parietal cortex in coordination of fingertip forces for grasp stability in manipulation. Journal of Neurophysiology, 90(5), 2978-2986.

Eichhorn, T. E., Gasser, T., Mai, N., Marquardt, C., Arnold, G., Schwarz, J., et al. (1996). Computational analysis of open loop handwriting movements in Parkinson's disease: a rapid method to detect dopamimetic effects. Mov Disord, 11(3), 289-297.

Elble, R. J. (2002). Tremor and dopamine agonists. Neurology, 58(4 Suppl 1), S57-62.

Eliasson, A.-C., Forssberg, H., Hung, Y.-C., \& Gordon, A. M. (2006). Development of hand function and precision grip control in individuals with cerebral palsy: a 13-year follow-up study. Pediatrics, 118(4), e1226-e1236.

Ellfolk, U., Joutsa, J., Rinne, J. O., Parkkola, R., Jokinen, P., \& Karrasch, M. (2014). Striatal volume is related to phonemic verbal fluency but not to semantic or alternating verbal fluency in early Parkinson's disease. J Neural Transm, 121(1), 33-40.

Evarts, E. V., Teravainen, H., \& Calne, D. B. (1981). Reaction time in Parkinson's disease. Brain, 104(Pt 1), 167-186.

Fagergren, A., Ekeberg, Ö., \& Forssberg, H. (2003). Control strategies correcting inaccurately programmed fingertip forces: model predictions derived from human behavior. Journal of neurophysiology, 89(6), 2904-2916.

Fahn, S. (2011). Classification of movement disorders. Mov Disord, 26(6), 947-957.

Fahn, S., Libsch, L. R., \& Cutler, R. W. (1971). Monoamines in the human neostriatum: topographic distribution in normals and in Parkinson's disease and their role in akinesia, rigidity, chorea, and tremor. J Neurol Sci, 14(4), 427-455.

Fellows, Ernst, J., Schwarz, M., Töpper, R., \& Noth, J. (2001). Precision grip deficits in cerebellar disorders in man. Clinical neurophysiology, 112(10), 1793-1802.

Fellows, Noth, J., \& Schwarz, M. (1998). Precision grip and Parkinson's disease. Brain, 121(9), 17711784.

Fellows, S. J., Kronenburger, M., Allert, N., Coenen, V. A., Fromm, C., Noth, J., et al. (2006). The effect of subthalamic nucleus deep brain stimulation on precision grip abnormalities in Parkinson's disease. [Research Support, Non-U.S. Gov't]. Parkinsonism Relat Disord, 12(3), 149-154.

Fellows, S. J., \& Noth, J. (2004). Grip force abnormalities in de novo Parkinson's disease. [Research Support, Non-U.S. Gov't]. Mov Disord, 19(5), 560-565. 
Ferraye, M. U., Ardouin, C., Lhommee, E., Fraix, V., Krack, P., Chabardes, S., et al. (2013). Levodoparesistant freezing of gait and executive dysfunction in Parkinson's disease. Eur Neurol, 69(5), 281-288.

Fishman, P. S. (2008). Paradoxical aspects of parkinsonian tremor. Mov Disord, 23(2), 168-173.

Forrest, K., Weismer, G., \& Turner, G. S. (1989). Kinematic, acoustic, and perceptual analyses of connected speech produced by parkinsonian and normal geriatric adults. J Acoust Soc Am, 85(6), 2608-2622.

Forsaa, E. B., Larsen, J. P., Wentzel-Larsen, T., Goetz, C. G., Stebbins, G. T., Aarsland, D., et al. (2010). A 12-year population-based study of psychosis in Parkinson disease. Arch Neurol, 67(8), 9961001.

Fox, S. H. (2013). Non-dopaminergic treatments for motor control in Parkinson's disease. Drugs, 73(13), 1405-1415.

Frank, M. J. (2005). Dynamic dopamine modulation in the basal ganglia: a neurocomputational account of cognitive deficits in medicated and nonmedicated Parkinsonism. J Cogn Neurosci, 17(1), 51-72.

Frank, M. J., Samanta, J., Moustafa, A. A., \& Sherman, S. J. (2007). Hold your horses: impulsivity, deep brain stimulation, and medication in parkinsonism. Science, 318(5854), 1309-1312.

Fung, V. S., Burne, J. A., \& Morris, J. G. (2000). Objective quantification of resting and activated parkinsonian rigidity: a comparison of angular impulse and work scores. Mov Disord, 15(1), 48-55.

Gangadhar, G., Joseph, D., \& Chakravarthy, V. S. (2008). Understanding Parkinsonian handwriting through a computational model of basal ganglia. Neural Comput, 20(10), 2491-2525.

Ghika, J., Wiegner, A. W., Fang, J. J., Davies, L., Young, R. R., \& Growdon, J. H. (1993). Portable system for quantifying motor abnormalities in Parkinson's disease. IEEE Trans Biomed Eng, 40(3), 276-283.

Giladi, N., McDermott, M. P., Fahn, S., Przedborski, S., Jankovic, J., Stern, M., et al. (2001). Freezing of gait in PD: prospective assessment in the DATATOP cohort. Neurology, 56(12), 1712-1721.

Goberman, A. M. (2005). Correlation between acoustic speech characteristics and non-speech motor performance in Parkinson Disease. Med Sci Monit, 11(3), CR109-116.

Gordon, Ingvarsson, P. E., \& Forssberg, H. (1997). Anticipatory control of manipulative forces in Parkinson's disease. [Research Support, Non-U.S. Gov't]. Exp Neurol, 145(2 Pt 1), 477-488.

Gordon, Westling, G., Cole, K. J., \& Johansson, R. S. (1993). Memory representations underlying motor commands used during manipulation of common and novel objects. Journal of Neurophysiology, 69(6), 1789-1796.

Grossman, M., Carvell, S., Gollomp, S., Stern, M. B., Vernon, G., \& Hurtig, H. I. (1991). Sentence comprehension and praxis deficits in Parkinson's disease. Neurology, 41(10), 1620-1626.

Gupta, A., Balasubramani, P. P., \& Chakravarthy, S. (2013). Computational model of precision grip in Parkinson's disease: A Utility based approach. [Original Research]. Frontiers in Computational Neuroscience, 7.

Gurney, K., Prescott, T. J., \& Redgrave, P. (2001). A computational model of action selection in the basal ganglia. II. Analysis and simulation of behaviour. Biol Cybern, 84(6), 411-423.

Halsband, U., \& Lange, R. K. (2006). Motor learning in man: a review of functional and clinical studies. J Physiol Paris, 99(4-6), 414-424.

Helie, S., Chakravarthy, S., \& Moustafa, A. A. (2013). Exploring the cognitive and motor functions of the basal ganglia: an integrative review of computational cognitive neuroscience models. Front Comput Neurosci, 7, 174.

Helmich, R. C., Hallett, M., Deuschl, G., Toni, I., \& Bloem, B. R. (2012). Cerebral causes and consequences of parkinsonian resting tremor: a tale of two circuits? Brain, 135(Pt 11), 32063226. 
Helmich, R. C., Janssen, M. J., Oyen, W. J., Bloem, B. R., \& Toni, I. (2011). Pallidal dysfunction drives a cerebellothalamic circuit into Parkinson tremor. Ann Neurol, 69(2), 269-281.

Hillis, A. E., Kane, A., Tuffiash, E., Beauchamp, N. J., Barker, P. B., \& Jacobs, M. A. (2002). Neural substrates of the cognitive processes underlying spelling: Evidence from MR diffusion and perfusion imaging Aphasiology, 16, 425-438.

Ho, A. K., lansek, R., Marigliani, C., Bradshaw, J. L., \& Gates, S. (1998). Speech impairment in a large sample of patients with Parkinson's disease. Behav Neurol, 11(3), 131-137.

Hughes, A. J., Daniel, S. E., Kilford, L., \& Lees, A. J. (1992). Accuracy of clinical diagnosis of idiopathic Parkinson's disease: a clinico-pathological study of 100 cases. Journal of Neurology, Neurosurgery, \& Psychiatry, 55(3), 181-184.

Illes, J., Metter, E. J., Hanson, W. R., \& Iritani, S. (1988). Language production in Parkinson's disease: acoustic and linguistic considerations. Brain Lang, 33(1), 146-160.

Ingvarsson, P. E., Gordon, A. M., \& Forssberg, H. (1997). Coordination of manipulative forces in Parkinson's disease. [Research Support, Non-U.S. Gov't]. Exp Neurol, 145(2 Pt 1), 489-501.

Ivry, R. B., Spencer, R. M., Zelaznik, H. N., \& Diedrichsen, J. (2002). The cerebellum and event timing. Ann N Y Acad Sci, 978, 302-317.

Jankovic, J. (2008). Parkinson's disease: clinical features and diagnosis. J Neurol Neurosurg Psychiatry, 79(4), 368-376.

Jankovic, J., McDermott, M., Carter, J., Gauthier, S., Goetz, C., Golbe, L., et al. (1990). Variable expression of Parkinson's disease: a base-line analysis of the DATATOP cohort. The Parkinson Study Group. Neurology, 40(10), 1529-1534.

Jankovic, J., \& Tolosa, E. (2007). Parkinson's disease and movement disorders. . Philadelphia: Lippincott Williams and Wilkins.

Jenkins, I. H., Fernandez, W., Playford, E. D., Lees, A. J., Frackowiak, R. S., Passingham, R. E., et al. (1992). Impaired activation of the supplementary motor area in Parkinson's disease is reversed when akinesia is treated with apomorphine. Ann Neurol, 32(6), 749-757.

Johansson. (1998). Sensory input and control of grip. Novartis Found Symp, 218, 45-59; discussion 59-63.

Johansson, \& Cole, K. J. (1994). Grasp stability during manipulative actions. Canadian journal of physiology and pharmacology, 72(5), 511-524.

Johansson, Hager, C., \& Riso, R. (1992). Somatosensory control of precision grip during unpredictable pulling loads. II. Changes in load force rate. Exp Brain Res, 89(1), 192-203.

Johansson, Riso, R., Hager, C., \& Backstrom, L. (1992). Somatosensory control of precision grip during unpredictable pulling loads. I. Changes in load force amplitude. Exp Brain Res, 89(1), 181191.

Johansson, \& Westling, G. (1984). Roles of glabrous skin receptors and sensorimotor memory in automatic control of precision grip when lifting rougher or more slippery objects. Exp Brain Res, 56(3), 550-564.

Johansson, \& Westling, G. (1988a). Coordinated isometric muscle commands adequately and erroneously programmed for the weight during lifting task with precision grip. [Research Support, Non-U.S. Gov't]. Exp Brain Res, 71(1), 59-71.

Johansson, \& Westling, G. (1988b). Programmed and triggered actions to rapid load changes during precision grip. [Research Support, Non-U.S. Gov't]. Exp Brain Res, 71(1), 72-86.

Jones, L. A., \& Lederman, S. J. (2006). Human hand function: Oxford University Press.

Kalia, L. V., Brotchie, J. M., \& Fox, S. H. (2013). Novel nondopaminergic targets for motor features of Parkinson's disease: review of recent trials. Mov Disord, 28(2), 131-144.

Kandel, E. R., Schwartz, J. H., \& Jessell, T. M. (2000). Principles of neural science (Vol. 4): McGraw-Hill New York. 
Kashiwabuchi, N., Ikeda, K., Araki, K., Hirano, T., Shibuki, K., Takayama, C., et al. (1995). Impairment of motor coordination, Purkinje cell synapse formation, and cerebellar long-term depression in GluR delta 2 mutant mice. Cell, 81(2), 245-252.

Kassubek, J., Juengling, F. D., Hellwig, B., Spreer, J., \& Lucking, C. H. (2002). Thalamic gray matter changes in unilateral Parkinsonian resting tremor: a voxel-based morphometric analysis of 3dimensional magnetic resonance imaging. Neuroscience Letters, 323(1), 29-32.

Kim, J. W., Lee, J. H., Kwon, Y., Kim, C. S., Eom, G. M., Koh, S. B., et al. (2011). Quantification of bradykinesia during clinical finger taps using a gyrosensor in patients with Parkinson's disease. Med Biol Eng Comput, 49(3), 365-371.

Kish, S. J., Shannak, K., \& Hornykiewicz, O. (1988). Uneven pattern of dopamine loss in the striatum of patients with idiopathic Parkinson's disease. Pathophysiologic and clinical implications. The New England Journal of Medicine, 318(14), 876-880.

Kleinow, J., \& Smith, A. (2000). Influences of length and syntactic complexity on the speech motor stability of the fluent speech of adults who stutter. J Speech Lang Hear Res, 43(2), 548-559.

Kleinow, J., \& Smith, A. (2006). Potential interactions among linguistic, autonomic, and motor factors in speech. Dev Psychobiol, 48(4), 275-287.

Koller, W. C., Busenbark, K., \& Miner, K. (1994). The relationship of essential tremor to other movement disorders: report on 678 patients. Essential Tremor Study Group. Ann Neurol, 35(6), 717-723.

Kompoliti, K., Wang, Q. E., Goetz, C. G., Leurgans, S., \& Raman, R. (2000). Effects of central dopaminergic stimulation by apomorphine on speech in Parkinson's disease. Neurology, 54(2), 458-462.

Krack, P., Batir, A., Van Blercom, N., Chabardes, S., Fraix, V., Ardouin, C., et al. (2003). Five-year follow-up of bilateral stimulation of the subthalamic nucleus in advanced Parkinson's disease. N Engl J Med, 349(20), 1925-1934.

Krack, P., Pollak, P., Limousin, P., Hoffmann, D., Benazzouz, A., Le Bas, J. F., et al. (1998). Opposite motor effects of pallidal stimulation in Parkinson's disease. Ann Neurol, 43(2), 180-192.

Kuhn, A. A., Tsui, A., Aziz, T., Ray, N., Brucke, C., Kupsch, A., et al. (2009). Pathological synchronisation in the subthalamic nucleus of patients with Parkinson's disease relates to both bradykinesia and rigidity. Exp Neurol, 215(2), 380-387.

Lange, K. W., Mecklinger, L., Walitza, S., Becker, G., Gerlach, M., Naumann, M., et al. (2006). Brain dopamine and kinematics of graphomotor functions. Hum Mov Sci, 25(4-5), 492-509.

Larson, K., Ramig, L. O., Scherer, R. C. (1994). Acoustic and glottographic voice analysis during drugrelated fluctuations in Parkinson's disease. J. Med. Speech Lang. Pathol., 2, 211-226.

Lee, Koh, S. B., Chae, S. W., Seo, W. K., Kwon do, Y., Kim, J. H., et al. (2012). Postural instability and cognitive dysfunction in early Parkinson's disease. The Canadian Journal of Neurological Sciences, 39(4), 473-482.

Lee, C., Grossman, M., Morris, J., Stern, M. B., \& Hurtig, H. I. (2003). Attentional resource and processing speed limitations during sentence processing in Parkinson's disease. Brain Lang, 85(3), 347-356.

Lees, A. J., Hardy, J., \& Revesz, T. (2009). Parkinson's disease. Lancet, 373(9680), 2055-2066.

Levelt, W. J., Roelofs, A., \& Meyer, A. S. (1999). A theory of lexical access in speech production. Behav Brain Sci, 22(1), 1-38; discussion 38-75.

Levy, R., Hutchison, W. D., Lozano, A. M., \& Dostrovsky, J. O. (2000). High-frequency synchronization of neuronal activity in the subthalamic nucleus of parkinsonian patients with limb tremor. $J$ Neurosci, 20(20), 7766-7775.

Lewis, Byblow, W. D., \& Walt, S. E. (2000). Stride length regulation in Parkinson's disease: the use of extrinsic, visual cues. Brain, 123 ( Pt 10), 2077-2090. 
Lewis, Du, G., Sen, S., Kawaguchi, A., Truong, Y., Lee, S., et al. (2011). Differential involvement of striato- and cerebello-thalamo-cortical pathways in tremor- and akinetic/rigid-predominant Parkinson's disease. Neuroscience, 177, 230-239.

Lewis, Foltynie, T., Blackwell, A. D., Robbins, T. W., Owen, A. M., \& Barker, R. A. (2005). Heterogeneity of Parkinson's disease in the early clinical stages using a data driven approach. J Neurol Neurosurg Psychiatry, 76(3), 343-348.

Lieberman, A. (2006). Are freezing of gait (FOG) and panic related? J Neurol Sci, 248(1-2), 219-222.

Lieberman, P., Kako, E., Friedman, J., Tajchman, G., Feldman, L. S., \& Jiminez, E. B. (1992). Speech production, syntax comprehension, and cognitive deficits in Parkinson's disease. Brain Lang, 43(2), 169-189.

Lo, R. Y., Tanner, C. M., Albers, K. B., Leimpeter, A. D., Fross, R. D., Bernstein, A. L., et al. (2009). Clinical features in early Parkinson disease and survival. Arch Neurol, 66(11), 1353-1358.

Louis, E. D., Levy, G., Cote, L. J., Mejia, H., Fahn, S., \& Marder, K. (2001). Clinical correlates of action tremor in Parkinson disease. Arch Neurol, 58(10), 1630-1634.

Louis, E. D., Tang, M. X., Cote, L., Alfaro, B., Mejia, H., \& Marder, K. (1999). Progression of parkinsonian signs in Parkinson disease. Arch Neurol, 56(3), 334-337.

Magill, P. J., Bolam, J. P., \& Bevan, M. D. (2001). Dopamine regulates the impact of the cerebral cortex on the subthalamic nucleus-globus pallidus network. Neuroscience, 106(2), 313-330.

Maillet, A., Krainik, A., Debu, B., Tropres, I., Lagrange, C., Thobois, S., et al. (2012). Levodopa effects on hand and speech movements in patients with Parkinson's disease: a FMRI study. PLoS One, 7(10), e46541.

Maner, K. J., Smith, A., \& Grayson, L. (2000). Influences of utterance length and complexity on speech motor performance in children and adults. J Speech Lang Hear Res, 43(2), 560-573.

Mansur, P. H., Cury, L. K., Andrade, A. O., Pereira, A. A., Miotto, G. A., Soares, A. B., et al. (2007). A review on techniques for tremor recording and quantification. Crit Rev Biomed Eng, 35(5), 343-362.

Marzke, M. W. (1997). Precision grips, hand morphology, and tools. American Journal of Physical Anthropology, 102(1), 91-110.

McLennan, J. E., Nakano, K., Tyler, H. R., \& Schwab, R. S. (1972). Micrographia in Parkinson's disease. J Neurol Sci, 15(2), 141-152.

Moreau, C., Ozsancak, C., Blatt, J. L., Derambure, P., Destee, A., \& Defebvre, L. (2007). Oral festination in Parkinson's disease: biomechanical analysis and correlation with festination and freezing of gait. Mov Disord, 22(10), 1503-1506.

Morgante, F., Barbuto, M., Ricciardi, L., Sorbera, C., Graziosi, A., Girlanda, P., et al. (2013). Stuttering Speech Disorder Is Related To Freezing Of Gait In Parkinson's Disease. Paper presented the Movement Disorders Sydney, Australia.

Morris, M. E., lansek, R., Matyas, T. A., \& Summers, J. J. (1996). Stride length regulation in Parkinson's disease. Normalization strategies and underlying mechanisms. Brain, 119 (Pt 2), 551-568.

Moustafa, A. A. (2014). Freezing of gait and response conflict in Parkinson's disease: computational directions. Front Comput Neurosci, 8, 7.

Moustafa, A. A., \& Poletti, M. (2013). Neural and behavioral substrates of subtypes of Parkinson's disease. Front Syst Neurosci, 7, 117.

Moyà-Solà, S., Köhler, M., \& Rook, L. (1999). Evidence of hominid-like precision grip capability in the hand of the Miocene ape Oreopithecus. Proceedings of the National Academy of Sciences, 96(1), 313-317.

Müller, F., \& Dichgans, J. (1994). Dyscoordination of pinch and lift forces during grasp in patients with cerebellar lesions. Exp Brain Res, 101, 485-492. 
Muralidharan, V., Balasubramani, P. P., Chakravarthy, V. S., Lewis, S. J., \& Moustafa, A. A. (2014). A computational model of altered gait patterns in parkinson's disease patients negotiating narrow doorways. Front Comput Neurosci, 7, 190.

Mure, H., Hirano, S., Tang, C. C., Isaias, I. U., Antonini, A., Ma, Y., et al. (2011). Parkinson's disease tremor-related metabolic network: characterization, progression, and treatment effects. Neuroimage, 54(2), 1244-1253.

Nagaoka, T., Katayama, Y., Kano, T., Kobayashi, K., Oshima, H., Fukaya, C., et al. (2007). Changes in glucose metabolism in cerebral cortex and cerebellum correlate with tremor and rigidity control by subthalamic nucleus stimulation in Parkinson's disease: a positron emission tomography study. Neuromodulation, 10(3), 206-215.

Naismith, S. L., \& Lewis, S. J. (2010). A novel paradigm for modelling freezing of gait in Parkinson's disease. J Clin Neurosci, 17(8), 984-987.

Napier, J. R. (1956). The prehensile movements of the human hand. J Bone Joint Surg Br, 38-B(4), 902-913.

Neely, K. A., Coombes, S. A., Planetta, P. J., \& Vaillancourt, D. E. (2013). Segregated and overlapping neural circuits exist for the production of static and dynamic precision grip force. Hum Brain Mapp, 34(3), 698-712.

Niazmand, K., \& al., e. (2011). Quantitative evaluation of Parkinson's disease using sensor based smart glove. .

Nutt, J. G., Bloem, B. R., Giladi, N., Hallett, M., Horak, F. B., \& Nieuwboer, A. (2011). Freezing of gait: moving forward on a mysterious clinical phenomenon. Lancet Neurol, 10(8), 734-744.

Oliveira, R. M., Gurd, J. M., Nixon, P., Marshall, J. C., \& Passingham, R. E. (1997). Micrographia in Parkinson's disease: the effect of providing external cues. I Neurol Neurosurg Psychiatry, 63(4), 429-433.

Pact, V., \& Giduz, T. (1999). Mirtazapine treats resting tremor, essential tremor, and levodopainduced dyskinesias. Neurology, 53(5), 1154.

Papapetropoulos, S., Katzen, H. L., Scanlon, B. K., Guevara, A., Singer, C., \& Levin, B. E. (2010). Objective quantification of neuromotor symptoms in Parkinson's disease: implementation of a portable, computerized measurement tool. Parkinsons Dis, 2010, 760196.

Park, H. K., Yoo, J. Y., Kwon, M., Lee, J. H., Lee, S. J., Kim, S. R., et al. (2014). Gait freezing and speech disturbance in Parkinson's disease. Neurol Sci, 35(3), 357-363.

Patrick, S. K., Denington, A. A., Gauthier, M. J., Gillard, D. M., \& Prochazka, A. (2001). Quantification of the UPDRS Rigidity Scale. IEEE Trans Neural Syst Rehabil Eng, 9(1), 31-41.

Phillips, J. G., Bradshaw, J. L., lansek, R., \& Chiu, E. (1993). Motor functions of the basal ganglia. Psychol Res, 55(2), 175-181.

Pinto, S., Ozsancak, C., Tripoliti, E., Thobois, S., Limousin-Dowsey, P., \& Auzou, P. (2004). Treatments for dysarthria in Parkinson's disease. Lancet Neurol, 3(9), 547-556.

Pinto, S., Thobois, S., Costes, N., Le Bars, D., Benabid, A. L., Broussolle, E., et al. (2004). Subthalamic nucleus stimulation and dysarthria in Parkinson's disease: a PET study. Brain, 127(Pt 3), 602615.

Pirker, W., Djamshidian, S., Asenbaum, S., Gerschlager, W., Tribl, G., Hoffmann, M., et al. (2002). Progression of dopaminergic degeneration in Parkinson's disease and atypical parkinsonism: a longitudinal beta-CIT SPECT study. Mov Disord, 17(1), 45-53.

Poletti, M., Emre, M., \& Bonuccelli, U. (2011). Mild cognitive impairment and cognitive reserve in Parkinson's disease. Parkinsonism Relat Disord, 17(8), 579-586.

Poletti, M., Frosini, D., Pagni, C., Baldacci, F., Nicoletti, V., Tognoni, G., et al. (2012). Mild cognitive impairment and cognitive-motor relationships in newly diagnosed drug-naive patients with Parkinson's disease. Journal of Neurology, Neurosurgery, \& Psychiatry, 83(6), 601-606. 
Poletti, M., Frosini, D., Pagni, C., Lucetti, C., Del Dotto, P., Tognoni, G., et al. (2011). The association between motor subtypes and alexithymia in de novo Parkinson's disease. J Neurol, 258(6), 1042-1045.

Poluha, P. C., Teulings, H. L., \& Brookshire, R. H. (1998). Handwriting and speech changes across the levodopa cycle in Parkinson's disease. Acta Psychol (Amst), 100(1-2), 71-84.

Pope, P., Wing, A. M., Praamstra, P., \& Miall, R. C. (2005). Force related activations in rhythmic sequence production. Neuroimage, 27(4), 909-918.

Probst-Cousin, S., Druschky, A., \& Neundorfer, B. (2003). Disappearance of resting tremor after "stereotaxic" thalamic stroke. Neurology, 61(7), 1013-1014.

Prochazka, A., Bennett, D. J., Stephens, M. J., Patrick, S. K., Sears-Duru, R., Roberts, T., et al. (1997). Measurement of rigidity in Parkinson's disease. Mov Disord, 12(1), 24-32.

Prodoehl, J., Corcos, D. M., \& Vaillancourt, D. E. (2009). Basal ganglia mechanisms underlying precision grip force control. Neurosci Biobehav Rev, 33(6), 900-908.

Prodoehl, J., Planetta, P. J., Kurani, A. S., Comella, C. L., Corcos, D. M., \& Vaillancourt, D. E. (2013). Differences in brain activation between tremor- and nontremor-dominant Parkinson disease. JAMA Neurol, 70(1), 100-106.

Prodoehl, J., Spraker, M., Corcos, D., Comella, C., \& Vaillancourt, D. (2010). Blood oxygenation leveldependent activation in basal ganglia nuclei relates to specific symptoms in de novo Parkinson's disease. Mov Disord, 25(13), 2035-2043.

Prodoehl, J., Yu, H., Wasson, P., Corcos, D. M., \& Vaillancourt, D. E. (2008). Effects of visual and auditory feedback on sensorimotor circuits in the basal ganglia. Journal of neurophysiology, 99(6), 3042-3051.

Qamhawi, Z., Towey, D., Shah, B., Pagano, G., Seibyl, J., Marek, K., et al. (2015). Clinical correlates of raphe serotonergic dysfunction in early Parkinson's disease. Brain, 138(Pt 10), 2964-2973.

Rajput, A. H. (1993). Diagnosis of PD. Neurology, 43(8), 1629-1630.

Rajput, A. H., Voll, A., Rajput, M. L., Robinson, C. A., \& Rajput, A. (2009). Course in Parkinson disease subtypes: A 39-year clinicopathologic study. Neurology, 73(3), 206-212.

Randhawa, B. K., Farley, B. G., \& Boyd, L. A. (2013). Repetitive transcranial magnetic stimulation improves handwriting in Parkinson's disease. Parkinsons Dis, 2013(Journal Article), 751925.

Redgrave, P., Rodriguez, M., Smith, Y., Rodriguez-Oroz, M. C., Lehericy, S., Bergman, H., et al. (2010). Goal-directed and habitual control in the basal ganglia: implications for Parkinson's disease. Nat Rev Neurosci, 11(11), 760-772.

Rigas, G., Tzallas, A. T., Tsalikakis, D. G., Konitsiotis, S., \& Fotiadis, D. I. (2009). Real-time quantification of resting tremor in the Parkinson's disease. Conf Proc IEEE Eng Med Biol Soc, 2009, 1306-1309.

Robbins, J. A., Logemann, J. A., \& Kirshner, H. S. (1986). Swallowing and speech production in Parkinson's disease. Ann Neurol, 19(3), 283-287.

Rochester, L., Yarnall, A. J., Baker, M. R., David, R. V., Lord, S., Galna, B., et al. (2012). Cholinergic dysfunction contributes to gait disturbance in early Parkinson's disease. Brain, 135(Pt 9), 2779-2788.

Rodriguez-Oroz, M. C., Lage, P. M., Sanchez-Mut, J., Lamet, I., Pagonabarraga, J., Toledo, J. B., et al. (2009). Homocysteine and cognitive impairment in Parkinson's disease: a biochemical, neuroimaging, and genetic study. Mov Disord, 24(10), 1437-1444.

Rosenberg-Katz, K., Herman, T., Jacob, Y., Giladi, N., Hendler, T., \& Hausdorff, J. M. (2013). Gray matter atrophy distinguishes between Parkinson disease motor subtypes. Neurology, 80(16), 1476-1484.

Rosenblum, S., Samuel, M., Zlotnik, S., Erikh, I., \& Schlesinger, I. (2013). Handwriting as an objective tool for Parkinson's disease diagnosis. J Neurol, 260(9), 2357-2361. 
Rossi, C., Frosini, D., Volterrani, D., De Feo, P., Unti, E., Nicoletti, V., et al. (2010). Differences in nigro-striatal impairment in clinical variants of early Parkinson's disease: evidence from a FPCIT SPECT study. Eur J Neurol, 17(4), 626-630.

Rusz, J., Cmejla, R., Ruzickova, H., Klempir, J., Majerova, V., Picmausova, J., et al. (2013). Evaluation of speech impairment in early stages of Parkinson's disease: a prospective study with the role of pharmacotherapy. J Neural Transm, 120(2), 319-329.

Sabatini, U., Boulanouar, K., Fabre, N., Martin, F., Carel, C., Colonnese, C., et al. (2000). Cortical motor reorganization in akinetic patients with Parkinson's disease: a functional MRI study. Brain, 123 (Pt 2), 394-403.

Salarian, A., \& al., e. (2007). Quantification of tremor and bradykinesia in Parkinson's disease using a novel ambulatory monitoring system. Biomedical Engineering, IEEE Transactions, 54(2), 313322.

Sapir, S., Ramig, L. O., \& Fox, C. M. (2011). Intensive voice treatment in Parkinson's disease: Lee Silverman Voice Treatment. Expert Rev Neurother, 11(6), 815-830.

Schiess, M. C., Zheng, H., Soukup, V. M., Bonnen, J. G., \& Nauta, H. J. (2000). Parkinson's disease subtypes: clinical classification and ventricular cerebrospinal fluid analysis. Parkinsonism Relat Disord, 6(2), 69-76.

Schillaci, O., Chiaravalloti, A., Pierantozzi, M., Di Pietro, B., Koch, G., Bruni, C., et al. (2011). Different patterns of nigrostriatal degeneration in tremor type versus the akinetic-rigid and mixed types of Parkinson's disease at the early stages: molecular imaging with 123I-FP-CIT SPECT. International Journal of Molecular Medicine, 28(5), 881-886.

Schlaier, J. R., Hanson, C., Janzen, A., Fellner, C., Hochreiter, A., Proescholdt, M., et al. (2014). Deep brain stimulation in Parkinson's disease: motor effects relative to the MRI-defined STN. Neurosurg Rev.

Schlerf, J. E., Spencer, R. M., Zelaznik, H. N., \& Ivry, R. B. (2007). Timing of rhythmic movements in patients with cerebellar degeneration. Cerebellum, 6(3), 221-231.

Schulz, G. M., \& Grant, M. K. (2000). Effects of speech therapy and pharmacologic and surgical treatments on voice and speech in Parkinson's disease: a review of the literature. $J$ Commun Disord, 33(1), 59-88.

Sekar, M. K., Arcelus, J., \& Palmer, R. L. (2010). Micrographia and hypophonia in anorexia nervosa. Int J Eat Disord, 43(8), 762-765.

Sepehri, B., Esteki, A., Ebrahimi-Takamjani, E., Shahidi, G. A., Khamseh, F., \& Moinodin, M. (2007). Quantification of rigidity in Parkinson's disease. Ann Biomed Eng, 35(12), 2196-2203.

Shapiro, M. B., Vaillancourt, D. E., Sturman, M. M., Metman, L. V., Bakay, R. A., \& Corcos, D. M. (2007). Effects of STN DBS on rigidity in Parkinson's disease. IEEE Trans Neural Syst Rehabil Eng, 15(2), 173-181.

Shibasaki, H., Tsuji, S., \& Kuroiwa, Y. (1979). Oculomotor abnormalities in Parkinson's disease. Arch Neurol, 36(6), 360-364.

Shibuki, K., Gomi, H., Chen, L., Bao, S., Kim, J. J., Wakatsuki, H., et al. (1996). Deficient cerebellar long-term depression, impaired eyeblink conditioning, and normal motor coordination in GFAP mutant mice. Neuron, 16(3), 587-599.

Shine, J. M., Frank, M. J., Moustafa, A. A., \& Lewis, S. J. (2013). Freezing of gait in Parkinson's disease is associated with functional decoupling between the cognitive control network and the basal ganglia. Brain, 136(Pt 12), 3671-3681.

Shine, J. M., Naismith, S. L., \& Lewis, S. J. (2011). The pathophysiological mechanisms underlying freezing of gait in Parkinson's Disease. J Clin Neurosci, 18(9), 1154-1157.

Siebner, H. R., Ceballos-Baumann, A., Standhardt, H., Auer, C., Conrad, B., \& Alesch, F. (1999). Changes in handwriting resulting from bilateral high-frequency stimulation of the subthalamic nucleus in Parkinson's disease. Mov Disord, 14(6), 964-971. 
Silverman, S. W., \& Ratner, N. B. (1997). Syntactic complexity, fluency, and accuracy of sentence imitation in adolescents. J Speech Lang Hear Res, 40(1), 95-106.

Skodda, S., Visser, W., \& Schlegel, U. (2011). Gender-related patterns of dysprosody in Parkinson disease and correlation between speech variables and motor symptoms. J Voice, 25(1), 7682.

Solida, A., Ghika, J., \& Vingerhoets, F. (2002). Acute dopaminergic challenge tests to assess postural/kinetic tremor of different origin: a case report. I Neurol Neurosurg Psychiatry, 73(2), 206-207.

Spencer, R. M., \& Ivry, R. B. (2005). Comparison of patients with Parkinson's disease or cerebellar lesions in the production of periodic movements involving event-based or emergent timing. Brain Cogn, 58(1), 84-93.

Spencer, R. M., Ivry, R. B., \& Zelaznik, H. N. (2005). Role of the cerebellum in movements: control of timing or movement transitions? Exp Brain Res, 161(3), 383-396.

Spiegel, J., Hellwig, D., Samnick, S., Jost, W., Mollers, M. O., Fassbender, K., et al. (2007). Striatal FPCIT uptake differs in the subtypes of early Parkinson's disease. J Neural Transm, 114(3), 331335.

Spielman, J., Mahler, L., Halpern, A., Gilley, P., Klepitskaya, O., \& Ramig, L. (2011). Intensive voice treatment (LSVT ${ }^{\oplus}$ LOUD) for Parkinson's disease following deep brain stimulation of the subthalamic nucleus. Journal of communication disorders, 44(6), 688-700.

Spraker, M. B., Yu, H., Corcos, D. M., \& Vaillancourt, D. E. (2007). Role of individual basal ganglia nuclei in force amplitude generation. Journal of neurophysiology, 98(2), 821-834.

Strick, P. L. (1976). Anatomical analysis of ventrolateral thalamic input to primate motor cortex. Journal of neurophysiology, 39(5), 1020-1031.

Suchowersky, O., Gronseth, G., Perlmutter, J., Reich, S., Zesiewicz, T., \& Weiner, W. J. (2006). Practice Parameter: neuroprotective strategies and alternative therapies for Parkinson disease (an evidence-based review): report of the Quality Standards Subcommittee of the American Academy of Neurology. Neurology, 66(7), 976-982.

Susman, R. L. (1998). Hand function and tool behavior in early hominids. Journal of Human Evolution, 35(1), 23-46.

Tabbal, S. D., Ushe, M., Mink, J. W., Revilla, F. J., Wernle, A. R., Hong, M., et al. (2008). Unilateral subthalamic nucleus stimulation has a measurable ipsilateral effect on rigidity and bradykinesia in Parkinson disease. Exp Neurol, 211(1), 234-242.

Takakusaki, K. (2008). Forebrain control of locomotor behaviors. Brain Res Rev, 57(1), 192-198.

Takakusaki, K., Oohinata-Sugimoto, J., Saitoh, K., \& Habaguchi, T. (2004). Role of basal gangliabrainstem systems in the control of postural muscle tone and locomotion. Prog Brain Res, 143, 231-237.

Tessitore, A., Amboni, M., Cirillo, G., Corbo, D., Picillo, M., Russo, A., et al. (2012). Regional gray matter atrophy in patients with Parkinson disease and freezing of gait. AJNR Am J Neuroradiol, 33(9), 1804-1809.

Tessitore, A., Amboni, M., Esposito, F., Russo, A., Picillo, M., Marcuccio, L., et al. (2012). Resting-state brain connectivity in patients with Parkinson's disease and freezing of gait. Parkinsonism Relat Disord, 18(6), 781-787.

Teulings, Contreras-Vidal, J. L., Stelmach, G. E., \& Adler, C. H. (2002). Adaptation of handwriting size under distorted visual feedback in patients with Parkinson's disease and elderly and young controls. J Neurol Neurosurg Psychiatry, 72(3), 315-324.

Teulings, \& Stelmach, G., E. (1991). Control of stroke size, peak acceleration, and stroke duration in Parkinsonian handwriting. Human Movement Science, 10, 315-334.

Thenganatt, M. A., \& Louis, E. D. (2012). Distinguishing essential tremor from Parkinson's disease: bedside tests and laboratory evaluations. Expert Rev Neurother, 12(6), 687-696. 
Toft, M., \& Dietrichs, E. (2011). Aggravated stuttering following subthalamic deep brain stimulation in Parkinson's disease--two cases. BMC Neurol, 11, 44.

Törnqvist, A. L., Schalén, L., Rehncrona, S., Lund, U., Neurokirurgi, Lunds, u., et al. (2005). Effects of different electrical parameter settings on the intelligibility of speech in patients with Parkinson's disease treated with subthalamic deep brain stimulation. Movement disorders, 20(4), 416-423.

Toth, C., Rajput, M., \& Rajput, A. H. (2004). Anomalies of asymmetry of clinical signs in parkinsonism. Mov Disord, 19(2), 151-157.

Trail, M., Fox, C., Ramig, L. O., Sapir, S., Howard, J., \& Lai, E. C. (2005). Speech treatment for Parkinson's disease. NeuroRehabilitation, 20(3), 205-221.

Tripoliti, E., Zrinzo, L., Martinez-Torres, I., Frost, E., Pinto, S., Foltynie, T., et al. (2011). Effects of subthalamic stimulation on speech of consecutive patients with Parkinson disease. Neurology, 76(1), 80-86.

Tucha, O., Mecklinger, L., Thome, J., Reiter, A., Alders, G. L., Sartor, H., et al. (2006). Kinematic analysis of dopaminergic effects on skilled handwriting movements in Parkinson's disease. $J$ Neural Transm, 113(5), 609-623.

Udden, J., \& Bahlmann, J. (2012). A rostro-caudal gradient of structured sequence processing in the left inferior frontal gyrus. Philos Trans R Soc Lond B Biol Sci, 367(1598), 2023-2032.

Uitti, R. J. (1998). Medical treatment of essential tremor and Parkinson's disease. Geriatrics, 53(5), 46-48, 53-47.

Ulloa, A. (2004). Mechanisms of human prehension. Paper presented at the Systems, Man and Cybernetics, 2004 IEEE International Conference on.

Vaillancourt, Mayka, M. A., Thulborn, K. R., \& Corcos, D. M. (2004). Subthalamic nucleus and internal globus pallidus scale with the rate of change of force production in humans. Neuroimage, 23(1), 175-186.

Vaillancourt, Prodoehl, J., Verhagen Metman, L., Bakay, R. A., \& Corcos, D. M. (2004). Effects of deep brain stimulation and medication on bradykinesia and muscle activation in Parkinson's disease. Brain, 127(Pt 3), 491-504.

Vaillancourt, Schonfeld, D., Kwak, Y., Bohnen, N. I., \& Seidler, R. (2013). Dopamine overdose hypothesis: evidence and clinical implications. Mov Disord, 28(14), 1920-1929.

Vaillancourt, Yu, H., Mayka, M. A., \& Corcos, D. M. (2007). Role of the basal ganglia and frontal cortex in selecting and producing internally guided force pulses. Neuroimage, 36(3), 793803.

Van Gemmert, A. W., Adler, C. H., \& Stelmach, G. E. (2003). Parkinson's disease patients undershoot target size in handwriting and similar tasks. J Neurol Neurosurg Psychiatry, 74(11), 15021508.

Van Gemmert, A. W., Teulings, H. L., Contreras-Vidal, J. L., \& Stelmach, G. E. (1999). Parkinson's disease and the control of size and speed in handwriting. Neuropsychologia, 37(6), 685-694.

Vandenbossche, J., Deroost, N., Soetens, E., Zeischka, P., Spildooren, J., Vercruysse, S., et al. (2012). Conflict and freezing of gait in Parkinson's disease: support for a response control deficit. Neuroscience, 206, 144-154.

Veltink, P. H., \& al., e. (1995). Towards a new method for kinematic quantification of bradykinesia in patients with Parkinson's disease using triaxial accelerometry Engineering in Medicine and Biology Society: IEEE 17th Annual Conference.

Vercruysse, S., Devos, H., Munks, L., Spildooren, J., Vandenbossche, J., Vandenberghe, W., et al. (2012). Explaining freezing of gait in Parkinson's disease: Motor and cognitive determinants. Mov Disord.

Vercruysse, S., Vandenberghe, W., Munks, L., Nuttin, B., Devos, H., \& Nieuwboer, A. (2014). Effects of deep brain stimulation of the subthalamic nucleus on freezing of gait in Parkinson's disease: a prospective controlled study. J Neurol Neurosurg Psychiatry, 85(8), 871-877. 
Von Coelln, F. R., Barr, E., Gruber-Baldini, A., Reich, S., Armstrong, M., \& Shulman, L. (2015). Motor Subtypes of Parkinson Disease are Unstable Over Time Neuology, 30(2), 253-258.

Wagle Shukla, A., Ounpraseuth, S., Okun, M. S., Gray, V., Schwankhaus, J., \& Metzer, W. S. (2012). Micrographia and related deficits in Parkinson's disease: a cross-sectional study. BMJ Open, 2(3).

Walker, H. C., Phillips, D. E., Boswell, D. B., Guthrie, B. L., Guthrie, S. L., Nicholas, A. P., et al. (2009). Relief of acquired stuttering associated with Parkinson's disease by unilateral left subthalamic brain stimulation. J Speech Lang Hear Res, 52(6), 1652-1657.

Wasson, P., Prodoehl, J., Yu, H., Corcos, D., \& Vaillancourt, D. (2007). Prediction and the basal ganglia. Society for Neuroscience, San Diego.

Weinberger, M., Hutchison, W. D., Lozano, A. M., Hodaie, M., \& Dostrovsky, J. O. (2009). Increased gamma oscillatory activity in the subthalamic nucleus during tremor in Parkinson's disease patients. Journal of Neurophysiology, 101(2), 789-802.

Wenzelburger, R., Zhang, B. R., Pohle, S., Klebe, S., Lorenz, D., Herzog, J., et al. (2002). Force overflow and levodopa-induced dyskinesias in Parkinson's disease. Brain, 125(4), 871-879.

Wiecki, T. V., \& Frank, M. J. (2010). Neurocomputational models of motor and cognitive deficits in Parkinson's disease. Prog Brain Res, 183, 275-297.

Wilcox, R. A., Cole, M. H., Wong, D., Coyne, T., Silburn, P., \& Kerr, G. (2011). Pedunculopontine nucleus deep brain stimulation produces sustained improvement in primary progressive freezing of gait. J Neurol Neurosurg Psychiatry, 82(11), 1256-1259.

Williams-Gray, C. H., Hampshire, A., Robbins, T. W., Owen, A. M., \& Barker, R. A. (2007). Catechol Omethyltransferase Val158Met genotype influences frontoparietal activity during planning in patients with Parkinson's disease. J Neurosci, 27(18), 4832-4838.

Wu, \& Hallett, M. (2013). The cerebellum in Parkinson's disease. Brain, 136(Pt 3), 696-709.

Wu, B., Han, L., Sun, B. M., Hu, X. W., \& Wang, X. P. (2014). Influence of deep brain stimulation of the subthalamic nucleus on cognitive function in patients with Parkinson's disease. Neurosci Bull, 30(1), 153-161.

Xia, R., \& Mao, Z. H. (2012). Progression of motor symptoms in Parkinson's disease. Neurosci Bull, 28(1), 39-48.

Yamada, K., Hamasaki, T., \& Kuratsu, J. (2014). Thalamic stimulation alleviates levodopa-resistant rigidity in a patient with non-Parkinson's disease parkinsonian syndrome. J Clin Neurosci, 21(5), 882-884.

Yin, H. H., \& Knowlton, B. J. (2006). The role of the basal ganglia in habit formation. Nat Rev Neurosci, 7(6), 464-476.

Young, R. W. (2003). Evolution of the human hand: the role of throwing and clubbing. Journal of Anatomy, 202(1), 165-174.

Yu, Sternad, D., Corcos, D. M., \& Vaillancourt, D. E. (2007). Role of hyperactive cerebellum and motor cortex in Parkinson's disease. Neuroimage, 35(1), 222-233.

Zaidel, A., Arkadir, D., Israel, Z., \& Bergman, H. (2009). Akineto-rigid vs. tremor syndromes in Parkinsonism. Current Opinion in Neurology, 22(4), 387-393.

Zakaria, R., Lenz, F. A., Hua, S., Avin, B. H., Liu, C. C., \& Mari, Z. (2013). Thalamic physiology of intentional essential tremor is more like cerebellar tremor than postural essential tremor. Brain Research, 1529, 188-199.

Zetusky, W. J., \& Jankovic, J. (1985). Laterality and symptom association in Parkinson's disease. Arch Neurol, 42(12), 1132-1133. 